\title{
Rainfall and Temperature Predictions: Implications for Rice Production in the Lower River Region of The Gambia
}

\author{
M'koumfida Bagbohouna ${ }^{1, *}$, D. Saberma Ragatoa ${ }^{2,3}$, Susan O. Simon ${ }^{4}$, Isidore Kodjovi Edjame ${ }^{3}$ \\ ${ }^{1}$ West African Science Service Centre on Climate Change and Adapted Land Use (WASCAL) Doctoral Research Programme in \\ Climate Change and Education, School of Agriculture and Environmental Sciences, University of The Gambia, The Gambia ORCID \\ ID: 0000-0002-0177-8645 \\ ${ }^{2}$ WASCAL Doctoral Research Programme in Climate Change and Land Use, Department of Civil Engineering, Kwame Nkrumah \\ University of Science and Technology (KNUST), Kumasi, Ghana ORCID ID: 0000-0002-3107-6134 \\ ${ }^{3}$ Department of Geography, Université de Lomé (UL), Togo \\ ${ }^{4}$ Centre for Dryland Agriculture (CDA), Department of Geography, Bayero University Kano (BUK), Nigeria \\ *Corresponding Author: fbagbo@gmail.com, bagbohouna.m@edu.wascal.org
}

Received January 23, 2020; Revised June 20, 2020; Accepted July 1, 2020

Copyright $(2020$ by authors, all rights reserved. Authors agree that this article remains permanently open access under the terms of the Creative Commons Attribution License 4.0 International License

\begin{abstract}
Climate change impacts have been the major subject of discussion for scientists from different fields of study, including the agriculture sector. This study investigates the effects and implications of future climate change on rice production in the Lower River Region of The Gambia. The study seeks the following specific objectives: i) Analyse temperature and rainfall trends over Lower River Region; ii) Determine the relationship between temperature, rainfalls and rice production in the study area; and iii) Simulate temperature, rainfalls and rice production as well as the existing relationship among those parameters in the future using seasonality. The trend was examined after an exploratory data analysis, a unit root test and a correlation analysis. The study revealed an increase in maximum temperature (Tmax) and a variation in minimum temperature (Tmin) where the increase is not constant over 1981-2015. Also, the harvested area, production and rainfall increased while yield decreased. The data was extrapolated to 2035 using a VARMA statistical forecast method. Ordinary Least Squares and robust linear regression models were applied to find out the future implications (2035 and subsequent near years) of the climate parameters on rice production using 1981 to 2015 -year series. The model shows that by 2035 , yields will negatively be affected by the increase in Tmax and positively by the very little variation in Tmin. But the risk is that the ratio is not balanced, the damages of Tmax will be greater than the good productions of Tmin. The Tmin will also decrease as a general trend occasioning severe conditions for rice production in the region. This reveals the effects of climate change on rice production even
\end{abstract}

though the relationship between climatic and rice variables remains low, because of the numerous parameters in rice production. This calls for an urgent need to improve rice varieties that will thrive well in the anticipated new climatic conditions (high yielding, heat tolerant, saline tolerant and early maturing) and promotion of good cultural practices that save water to cope with future climate. This study suggests that more studies should include other parameters of rice production for improved predictions.

Keywords Climate Change, Rice Production, Statistical Forecast, Multiple Linear Regression, VARMA Model, Trend and Seasonality

\section{Introduction}

Climate variability and change spawn both threats and prospects. Moreover, available research and case studies confirm that developing countries face the enormous impacts and risks associated with climate variability and change as a result of low adaptive capacity (Kotir, 2011). There is a growing body of consensus that shows that climate variability and change fall disproportionately on the poorest and most vulnerable populations, especially developing countries. Climate change has been predicted to decrease agricultural productivity by as much $20 \%$ in Africa, Asia and Latin America at the end of this century (Adhikari, et al., 2015; Komba \& Muchapondwa, 2015). 
Countries with an agrarian economy are most threatened by climate change and variability (IPCC, 2007). Moreover, a study of Al-Amin et al. (2016) concluded that by 2100, agriculture in Sub-Saharan Africa, including The Gambia may likely face yield reduction and low GDP due to climate change. The economy of The Gambia is mainly dependent on rain-fed agriculture and services (UNECA, 2017). It is clear that factors such as climate change endangers economic stability in the country (UNECA, 2017). For instance, analyses from 1943 to 1983 of climate parameters (temperature and rainfall) of the country depicted an increase of $1{ }^{\circ} \mathrm{C}$ in the annual mean temperature and $20 \%$ to $25 \%$ reduction in the annual mean rainfall (AGRER, 2017). This could result in devastative impacts on the livelihood support systems of farmers, especially rice farmers in the country. Any severe decline in the production of rice, the major basic food of the country (the auto-consumption of which is about $60-70 \%$ ) will have a serious impact on the food security level of rural households and even those in the urban areas (Fatajo, 2009).

Rice (Oryza sativa L.) is the second most important crop in the world after wheat, with about 522 metric tonnes being globally produced. It accounts for $56 \%$ of the cultivated land in The Gambia. It is the staple food consumed and accounts for $25-35 \%$ of total cereal production of the country (Fatajo, 2009) with the agricultural sector accounting for $20 \%$ of GDP (GBOS, 2017 ) and $75 \%$ of the country's labour force (NPC, 2009). Rice farming is therefore an important source of livelihoods and incomes to thousands of Gambians (NAPA, 2007). Rice farming in the country is practised both in lowlands and uplands during the wet season because rice production requires water for irrigation (Silva et al., 2007). There is consensus that temperature and rainfall will continue to increase and decrease respectively in the tropics and sub-tropics (Alavian et al., 2009). For this reason, predicting future temperature and rainfall as well as their impacts at country level could be of great importance to the agricultural sector.

Few studies in The Gambia focused on the productivity of major crops and how they have been impacted by historical climate change (Hayes et al., 1997; Akon-yamga et al., 2011). For example, Bojang et al. (2016) used a Linear Programming model to assess how to maximize farmers' net profit under a set of constraints (plant area and water). The study concluded that about $50 \%$ of annual revenue of the farm could be achieved through optimum water use efficiency.

Thus, this study could provide insights for planning strategies in order to meet the increased demands for rice in the country during this century. While recent studies focused on modelling future impacts of climate change on rice production in some countries in Asia (Basak et al., 2010; Silva et al., 2007; Kropff, et al., 1997), little is being done in Africa, especially at country level.

There is therefore, a dearth of knowledge on the implications of climatic parameters (temperature and rainfall, for instance) on rice crops in Africa and more especially in countries where rice is the staple food as it is the case for The Gambia. It is against this background that this study seeks to analyse future climatic parameters (temperature and rainfall) and their implications on rice production in the country. The study will examine the trends and relationship (current and future) between climatic variables (temperature and rainfall) and rice production to reveal the potential impacts of climate change on rice production in The Gambia in the near future. This will inform agriculture experts, academics, researchers, government, NGOs, rice farmers and any other stakeholders on the strategies that can improve rice production in a climate change context to meet the increasing demand of rice in the country.

\section{Materials and Methods}

\subsection{Study Area}

The study was carried out in the Lower River Region of The Gambia (Figure 1). The region of a total land surface area of $1,618 \mathrm{Km}^{2}(\mathrm{GBoS}, 2017)$, is sited in the southern bank of River Gambia and stretches about ninety-five kilometres $(95 \mathrm{~km})$ from Brumen Bridge in the west to Sofanyama Bridge in the east (Government of The Gambia, 2007) between $13034^{\prime} 0$ " $\mathrm{N}$ and longitude $14047^{\prime} 0$ " $\mathrm{W}$. The overall population in the region is approximately 81,042 inhabitants (GBoS, 2013) with over $80 \%$ relying on agriculture and natural resources as a source of livelihood and household income (Government of The Gambia, 2007). With a Sudano-Sahelian climate characterized by a short rainy season from June to October, the mean annual rainfall in the region varies from $900 \mathrm{~mm}$ in the South West to about $600 \mathrm{~mm}$ in the North East. Ranging from $25^{\circ} \mathrm{C}$ to $28{ }^{\circ} \mathrm{C}$, mean temperatures are generally higher in the Eastern part of the country. It is noted that rice is the major crop cultivated in the region (MOA, 2013). Owing to low water flows of the River Gambia and increase of evaporation due to climate change, rice production hectares in the region had dropped (Webb, 1992). 


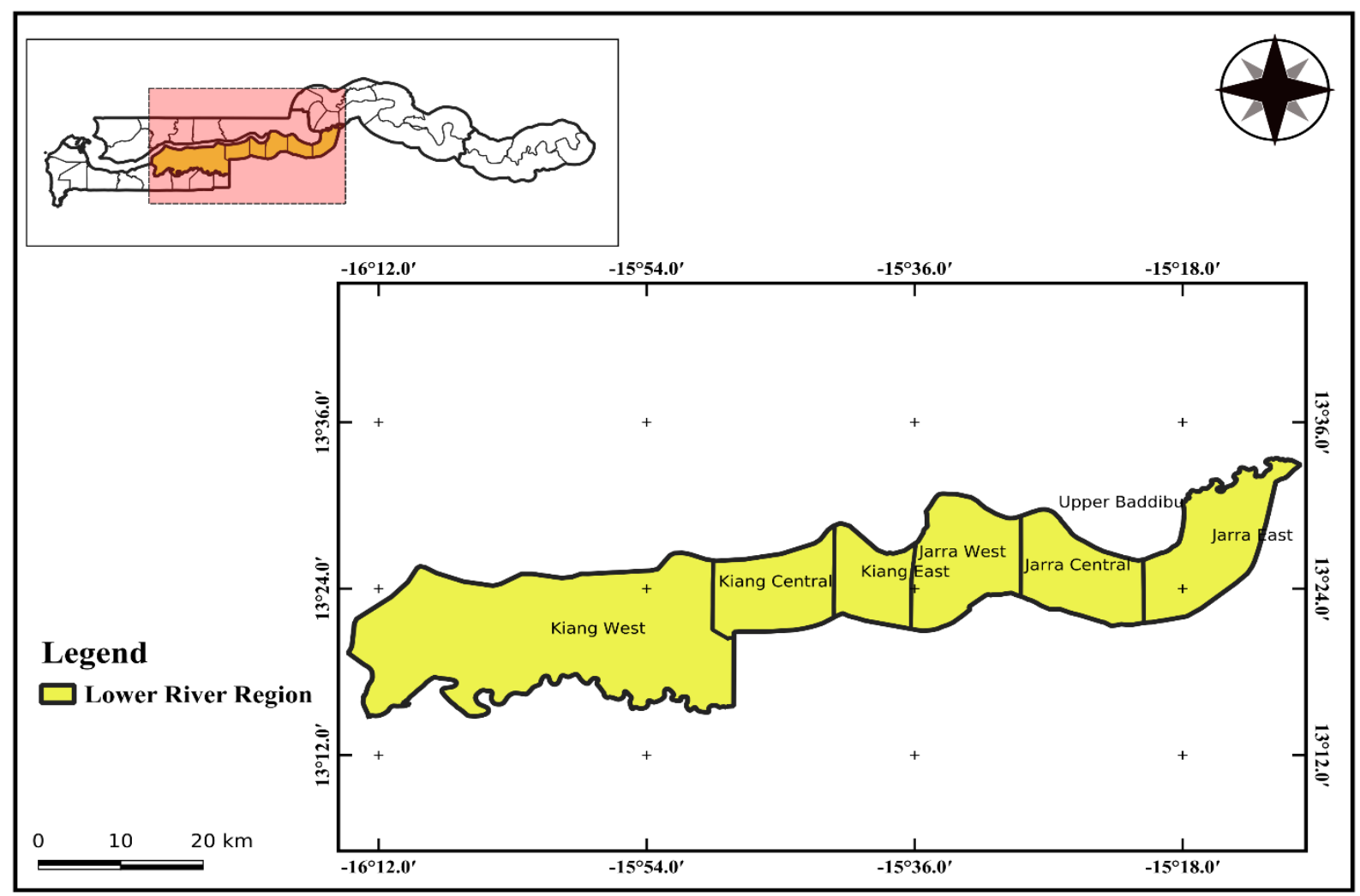

Figure 1. Study Area, Lower River Region (LLR), The Gambia

\subsection{Data Collection and Analysis}

Monthly Data, from 1981 to 2015, (minimum and maximum temperature and rainfall data) for this study were collected from the Department of Water Resources (DWR) of The Gambia. The historical data for rice production of the region was obtained from the Department of Planning Services of Agriculture for the same period. The collected data were specifically for the Lower River Region of The Gambia, and the datasets were controlled for quality and cleaned up to enable appropriate analysis. To get the annual data from the monthly observations of climate parameters, a re-sampling method was used in python with a function to compute the sum and another to compute the mean of all the grouped values by date index, respectively for rainfall and temperature data (Ragatoa et al., 2018).

\subsubsection{Exploratory Data Analysis (EDA)}

Exploratory Data Analysis (EDA) was performed after the data had been checked for their structure and character. The EDA aims to (i) maximize insight into a data set; (ii) uncover underlying structure; (iii) extract important variables; (iv) detect outliers and anomalies; (v) test underlying assumptions; (vi) develop parsimonious models; and (vii) determine optimal factor settings (Abzalov, 2016; Andrienko \& Gennady, 2006; Bolker, 2019; Gelman, 2004; Jersky, 2009). In this analysis, the points (i - iv) were tested.

This set of investigation determines how the analysis will be carried out (Weihs, 2005). Python programming language was used for the whole data analysis. The missing values were checked and filled in using the mean nearest interpolation for each series of data. A statistical descriptive analysis was also performed to determine the contours of the data and the distribution. The non-parametric ANOVA Kruskal-Wallis H-test for 2 or more groups was performed on the annual data, to figure out the differences in the groups of categorical data and the variations in the datasets (Christensen, 2011; Johnson \& Girden, 2006; Judd et al., 2018; Martin, 1000; McHugh, 2011; Shaw \& Mitchell-Olds, 1993; Smalheiser, 2017; Sthle \& Wold, 1989; Vogt, 2015).

\subsubsection{Trend Analysis and Seasonality in the Data}

As in Mushtaq (2011), the stationarity (with the assumption that the mean/variance or covariance is constant and does not change over time) was tested using the Augmented Dickey Fuller Test (ADF Test), a "Unit Root Tests" (Hall, 1994; Im, Pesaran, \& Shin, 2003). The null hypothesis $\left(\mathrm{H}_{0}\right)$ was that the time series possesses a unit root and is non-stationary; the alternate hypothesis $\left(\mathrm{H}_{1}\right)$ said, there is no unit root in the series, implying stationarity in the dataset (Phillips \& Perron, 1988; Pourahmadi, 1986; Priestley \& Rao, 1969; Refinetti, 2004). Thus, if the $\mathrm{p}$-value in the test is less than the significance level (0.05), the null hypothesis is rejected and the conclusion is that the data is stationary. The differencing method was applied to 
the original series when they were found non-stationary. The differencing method is done by subtracting the next value of the series by the current value and this all through the series.

To analyse the temperature and rainfall seasonal estimates, a rolling average (for each point in the time, the average of the points is taken on either side of it) was performed on a 12 months window for the monthly data. The maximum temperature (Tmax) and minimum temperature (Tmin) and rainfall data were checked to determine their trends (Baker, 1977). The seasonal difference was explored and the peak difference checked for each series. Periodicity and auto-correlation were applied to detect if it repeats itself at an equally spaced interval (12 months, but only for the monthly data). The same analyses (except for the periodicity) were computed on the annual data (using a 6-year window for the rolling mean), the annual data comprised the yield, the harvested area and the annual production for rice and the climate parameters (temperature and rainfall) (Gasparella et al., 2011).

The time-series decomposition method used allowed to decompose the time series into three distinct components: trend, seasonality, and noise to dissociate the trend and seasonality for the forecast. This method uses the Seasonal and Trend decomposition based on the Loess (Localized Regression) method (STL) (Aguilera et al., 2015; Carslaw, 2005; Cleveland et al.,1990; Jiang, Liang, Wang, \& Xiao, 2010; Mhamdi, Poggi, \& Jaïdane, 2011; Rojo et al., , 2017; Sanchez-Vazquez, et al., 2012; Silawan et al., 2008; Xiong, $\mathrm{Li}, \& \mathrm{Bao}, 2018)$, a filtering algorithm used to decompose time series into the three aforementioned components based on the application of the Loess smoother. The correlation coefficient (Bland \& Altman, 1986) was also computed to check for possible relationships between the variables in the data. This check was performed only on the annual data (the yield, the harvested area and the annual production were added to the climate parameters) (Cohen, 1988; Dendukuri \& Reinhold, 2005; Goldstein, Cohen, \& Cohen, 2006; Kissling, 2017; Markowitz, 2018; McKean, 1969; Mukaka, 2012; Muller, 2012; Pak \& Oh, 2010; Wassertheil \& Cohen, 2006).

\subsubsection{Partial Autocorrelation and Autocorrelation Analysis}

The partial autocorrelation and autocorrelation were checked (Haining, 2015; Ord \& Getis, 2001; Mills \& Mills, 2014; Schiegg, 2003; Segurado, Araújo, \& Kunin, 2006; Woolrich et al., 2001). A significantly autocorrelated series means the previous values of the series (lags) may be helpful in predicting the current values. The partial autocorrelation imparts similar information but it expresses the pure correlation of the series and their lags but does not consider the correlation contributions from the intermediate lags. The best model forecast parameters were determined using Autocorrelation (ACF) and Partial Autocorrelation (PACF) methods on the first order difference of the original dataset. PACF considers the direct effects while the ACF takes into account the direct as well as indirect effect of prior records on the current values of a variable. The autocorrelation function helps in identifying the good time series model parameters (Bisgaard \& Kulahci, 2009; Chen, 2012; Hyndman, 2015; Kumar \& Jain, 2010; Kumar et al., 2014; Ngo, 2013; Parmar \& Bhardwaj, 2014; Sovann, Nallagownden, \& Baharudin, 2014; Suhartono, 2011; Tarno et al., 2012; Vinod, 2006; Yurekli, Kurunc, \& Ozturk, 2005).

\subsubsection{Regression Analysis}

Regression analysis is an important field in statistics and machine learning. With the regression method, this study reveals the existing correlation between the rainfall data and the temperature evolution. For this study, the multiple regression analysis was performed using the Ordinary Least Square (OLS) method - a generalized linear modelling technique that models and estimates the relationship between one or more independent variables and a dependent variable which has been recorded generally as a time series. The dependent variable or predictor $\mathrm{Y}$ is predicted by multiple explanatory variables:

$$
\mathrm{Y}=\mathrm{B} \_1 * \mathrm{x} \_1+\mathrm{B} \_2 * \mathrm{x} \_2+\ldots+\mathrm{B} \_\mathrm{n} * \mathrm{x} \_\mathrm{n}+\boldsymbol{\alpha}
$$

Rainfall is the output/dependent variable for the monthly climate parameters (rainfall and temperature). It was set to determine whether rice production is affected by climate variabilities under global warming in the region. The same analyses were performed for the second set of data that comprised the annual climate parameters and the rice data (the harvested area, yield and harvested production). The model was built using rainfall as the dependent variable for climate parameters (temperature and rainfall) and rice production. Also, the yield and the production were considered as a dependent variable. A robust linear regression (RLM) model was used to determine the future relationships between the rice production series and the climatic parameters. A robust regression is a comprehensive term for methods of linear regression that intends to mitigate the effect of outliers (and/or heteroscedasticity). The mean absolute deviation (MAD) scale factor or scale estimator was used with the $\mathrm{H}_{1}$ covariance type and a confidence level between $0.25 \%$ and $97.5 \%$.

\subsubsection{Prediction of Climate Parameters and Rice Production (Using VARMA Model)}

Usual time series forecasting methods focus mostly on simple or linear relationships. They are advanced and perform well on an all-encompassing prediction job, provided the data is appropriately prepared and the method is well set up and fixed.

The VARMA (Vector Autoregression Moving-Average) method used considers the possible relations in the time series' variables. The VARMA method models the next 
step in each time series using an ARMA (Auto-Regressive Moving Average) model. The VARMA model is based on the AR (Autoregression) model (Aboagye-Sarfo et al., 2015; Du Toit \& Browne, 2007) and the MA (Moving Average).

AR model performs with the simple rule that the value of variable $\mathrm{X}$ at time is defined by the values of previous $\mathrm{X}$. The relationship could be formulated as follows:

$$
X_{t}=\sum_{j=1}^{p} \phi_{j} X_{t-j}+\omega_{t} \quad \text { (2) (Guidolin, 2018) }
$$

The Vector Autoregression (VAR) statistical model is used to model and determine the linear relationship of multiple time series. VAR models generalize the univariate autoregressive model (AR model) by modelling the next step in each time series or input variable using an AR model. It is considered the generalization of AR methods to multiple parallel time series, such as multivariate time series. The notation for the model involves specifying the order for the $\mathrm{AR}(\mathrm{p})$ model as parameters to a VAR function $(\operatorname{VAR}(\mathrm{p}))$. The Vector Autoregression Moving Average (VARMA) method has a similar process to the VAR method but uses a moving-average time series as does an ARMA model. In the ARMA model, AR is Auto-regressive and MA is Moving Averages. VARMA considers the ARMA model applied to multivariate time series. VARMA models are preferred because of the theoretical advantages they have over a pure VAR process such as the closed under linear transformation (Kascha \& Trenkler, 2014). In the case of VARMA, the notation for the model refers to two parameters $(p, q)$ and needs to specify the order for the $\mathrm{AR}(\mathrm{p})$ and MA(q) models as parameters to a VARMA function, e.g. VARMA(p, q). The VARMA method is applied here because of the objective to determine the relationship between climate parameters and rice production variables and it is suitable for multivariate time series. VARMA models are suitable models for producing linear forecasts of sets of time series variables (Luetkepohl, 2004). It is noted:

$$
A_{0 y t}=A_{1} y_{t}+\ldots+A_{p} y_{t-p} M_{0} u_{t}+M_{1} u_{t-1}+\ldots+M_{q} u_{t-q}, t=0, \pm 1, \pm 2, \ldots
$$

Finally, a robust regression algorithm was used on the VARMA predicted values to 2035 to show the collinearity and influence of climate parameters on rice production, knowing that ordinary least squares (OLS) method is very sensitive to outlying observations (Ali \& Qadir, 2015). To deal with this problem of outliers, Huber introduced the notion of M-estimators in 1964 (Hampel et al., 1986) that was improved on in several research works. This analysis of M-estimators generally seeks to reduce the influence of observations that behave as outliers (Andrews \& Pregibon, 1978). Tukey's bi-weight or Huber's method is generally used as both of them are M-Estimators and use iteratively reweighted least squares. In this study, Andrew's wave for M Estimation (Andrew Wave norm) was employed. The distant outliers are completely rejected in a shift process, allowing a transitional zone of increasing doubt, hence much more efficient than "hard" rejection rules; they are usually better than Huber-estimators (Ali \& Qadir, 2015).

\section{Results and Discussion}

The results considered the annual and monthly results in order to understand the effect of temperature and rainfall variability on rice production in the LRR of The Gambia. The extrapolation of the data to 2035 shows that there will be a change in both temperature and rainfall parameters as well as in the rice production and yield.

\subsection{Exploratory Data Analysis (EDA)}

The data were filled using the mean value interpolation for each series and resampled in order to perform descriptive statistics. The minimum temperature (Tmin) varied from $17^{\circ} \mathrm{C}$ to $25^{\circ} \mathrm{C}$ and the maximum temperature ranged from $30^{\circ} \mathrm{C}$ to $47^{\circ} \mathrm{C}$. The precipitation dataset ranges from $00 \mathrm{~mm}$ to $463 \mathrm{~mm}$ the month during the rainy season. The standard deviation revealed that the precipitation was highly dispersed, especially in the third $(0-116)$ and fourth (116 - 463) quantiles. The non-parametric ANOVA results (statistic $=342.377, \mathrm{p}$-value $=4.505 \mathrm{e}-75)$ being significant, we can reject the null hypothesis that the population medians of all the groups are equal.

The annual data showed similar distribution. But in this set of data, rice production, yield and harvested area were added. The rainfall was still highly variable but relatively dispersed in the quantile repartition.

The annual group non-parametric ANOVA $\mathrm{H}$ statistic is 179.616 and the p-value is statistically significant $(6.462$ e-37). The annual group series is more dispersed compared to the monthly group series; this is due to the integration of the high values from rice variables but with relatively low dispersion in each series. For example, the productions show that the series varies between $1500-3500$ metric tonnes (mt) around the mean that is about $2900 \mathrm{mt}$.

\subsection{Trend Analysis, Seasonality and Periodicity}

\subsubsection{Stationarity Test and Data Transformation}

The monthly dataset in Figure 2a clearly shows the range variation of the temperature and rainfall (precipitation) with peak values at some periods in the time series. Stationarity in the time series can also be observed. The patterns of the plots can be distinguished as we observe seasonality but the trend is not very clear. The annual series in Figure $2 b$ does not reveal, at first look to the plot, any seasonality nor a clear trend of the time series. 

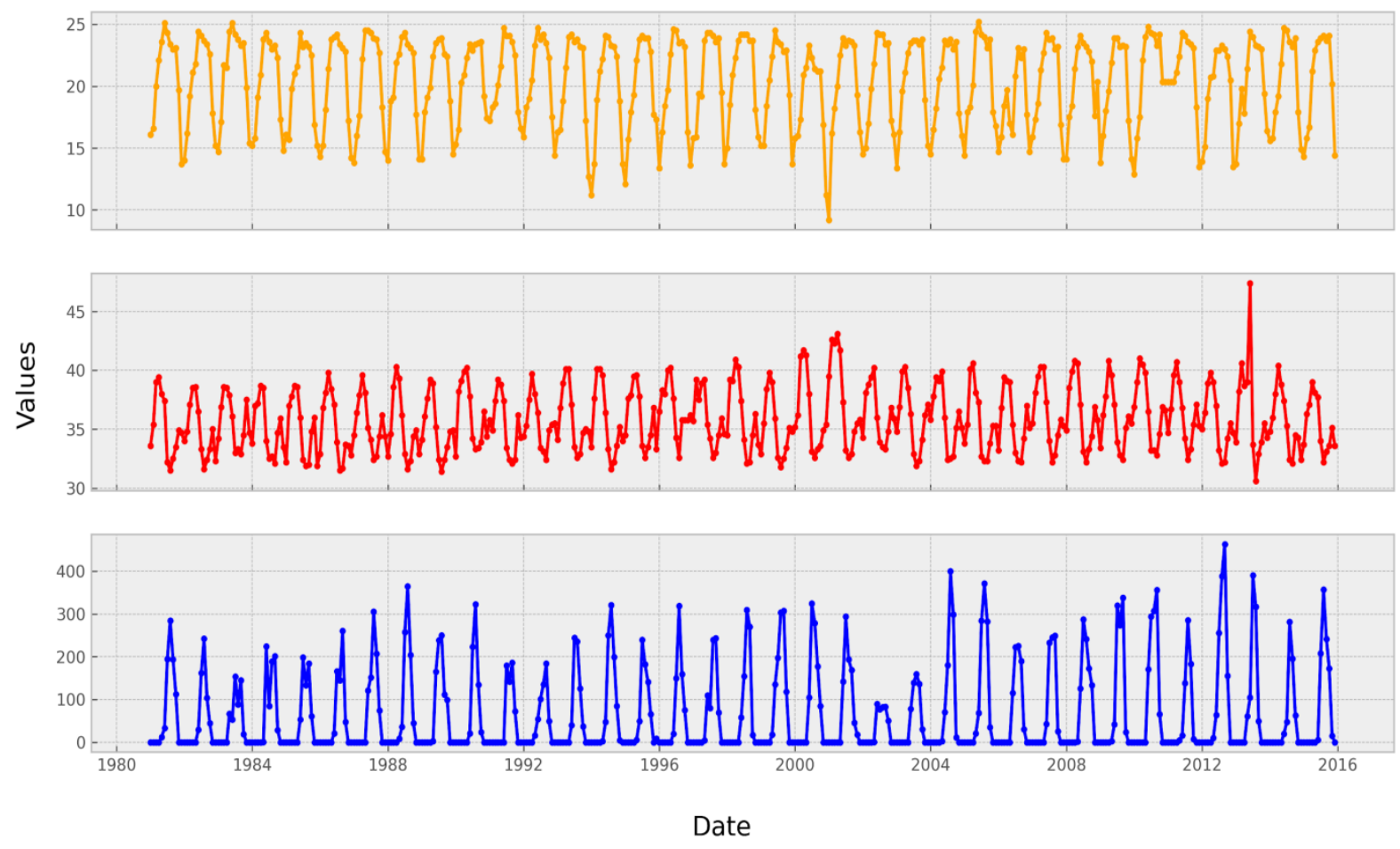

a $\rightarrow \operatorname{tmin} \rightarrow \operatorname{tmax} \rightarrow$ precipitation $\rightarrow$ areas $\rightarrow$ yields $\rightarrow$ production

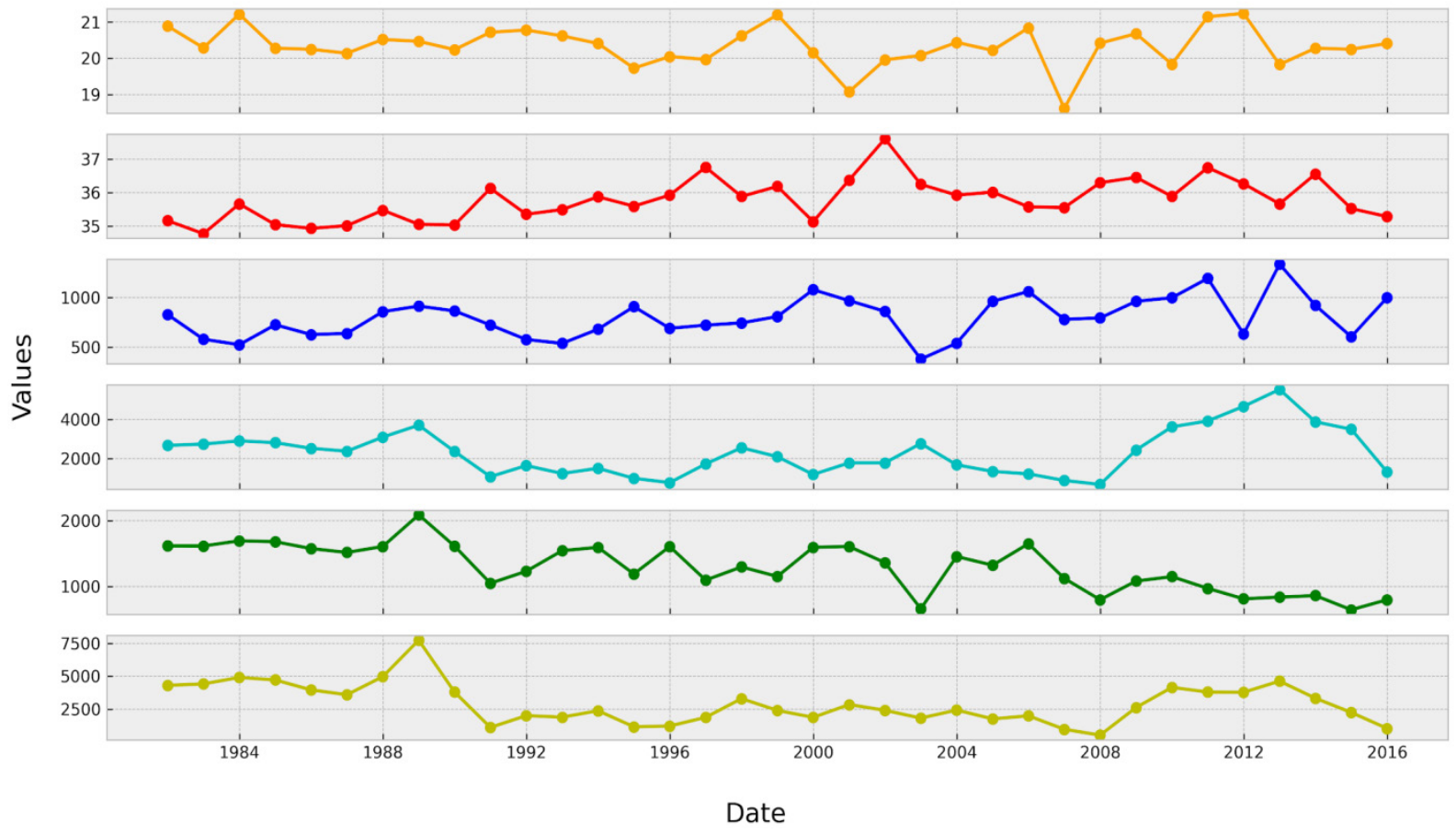

b

Figure 2. Visualization of the time series; a monthly series; $\mathbf{b}$ annual series with rice production data 
The annual data reveals the behaviour of the series. Rice production shows patterns that are similar to the harvested area. The Augmented Dickey-Fuller (ADF) test, in this analysis, was considered for the stationarity test. The significance level was fixed at the default value of $5 \%$. Table 4 shows that the results of the monthly climatic parameters passed the ADF test as in Table 4, as well as in Table 5 for the annual series.

Table 1. Augmented Dickey-Fuller test results (Monthly data)

\begin{tabular}{|c|c|c|c|}
\hline \multicolumn{4}{|c|}{ Augmented Dickey-Fuller test } \\
\hline Test Results & Tmin & Tmax & Prec \\
\hline ADF Test Statistic & -5.612 & -3.500869 & -3.635 \\
\hline p-value & 0.000001 & 0.007965 & 0.005121 \\
\hline Observations Used & 402 & 405 & 408 \\
\hline Critical Value (5\%) & -2.869 & -2.869 & -2.869 \\
\hline Decision & True & True & True \\
\hline
\end{tabular}

* The yellow colour shows the 5\% default significance level.

In a stationarity test if the test statistic is less than the critical value, we can reject the null hypothesis $\mathrm{H}_{0}$, meaning that the series is stationary. When the test statistic is greater than the critical value, we fail to reject the null hypothesis (which means the series is not stationary). The monthly series are stationary for the $5 \%$ critical value as well as the $10 \%$ critical value. Only $1 \%$ has disparities. The $\mathrm{p}$-values from the ADF test is much lower than the 0.05 default significance p-value level, hence we fail to accept the $\mathrm{H}_{0}$, meaning stationarity exists in the monthly series that is considered only for climatic data.

The annual series showed the same results for the climate parameters and the rice production series, but the other series showed different results (area, yields and production were not stationary). This can be seen in Table 5 where the $5 \%$ critical values are lower than the test statistic values except for the area, yields and production series.

The harvested area and the yield series were not stationary. To make them stationary, the first order differencing was used for the yield and the harvested area series. Figure 3 shows the adjusted yield and harvested area series after the first order differencing (subtracting the next value by the current value only at the original series level) of the data, making it stationary.

Table 2. Augmented Dickey-Fuller test results (Annual data)

\begin{tabular}{|c|c|c|c|c|c|c|}
\hline \multicolumn{9}{|c|}{ Augmented Dickey-Fuller test } \\
\hline Test Results & Tmin & Tmax & Prec & Area & Yields & Production \\
\hline ADF Test Statistic & -5.84 & -3.79 & -4.48 & -2.73 & 0.53 & -3.02 \\
\hline p-value & $3.778198 \mathrm{e}-07$ & 0.003061 & 0.000211 & 0.069304 & 0.985811 & 0.032887 \\
\hline Critical Value (5\%) & -2.95 & -2.95 & -2.95 & -2.96 & -2.97 & -2.95 \\
\hline Decision & True & True & True & False & False & True \\
\hline
\end{tabular}

* The yellow colour shows the 5\% default significance level.

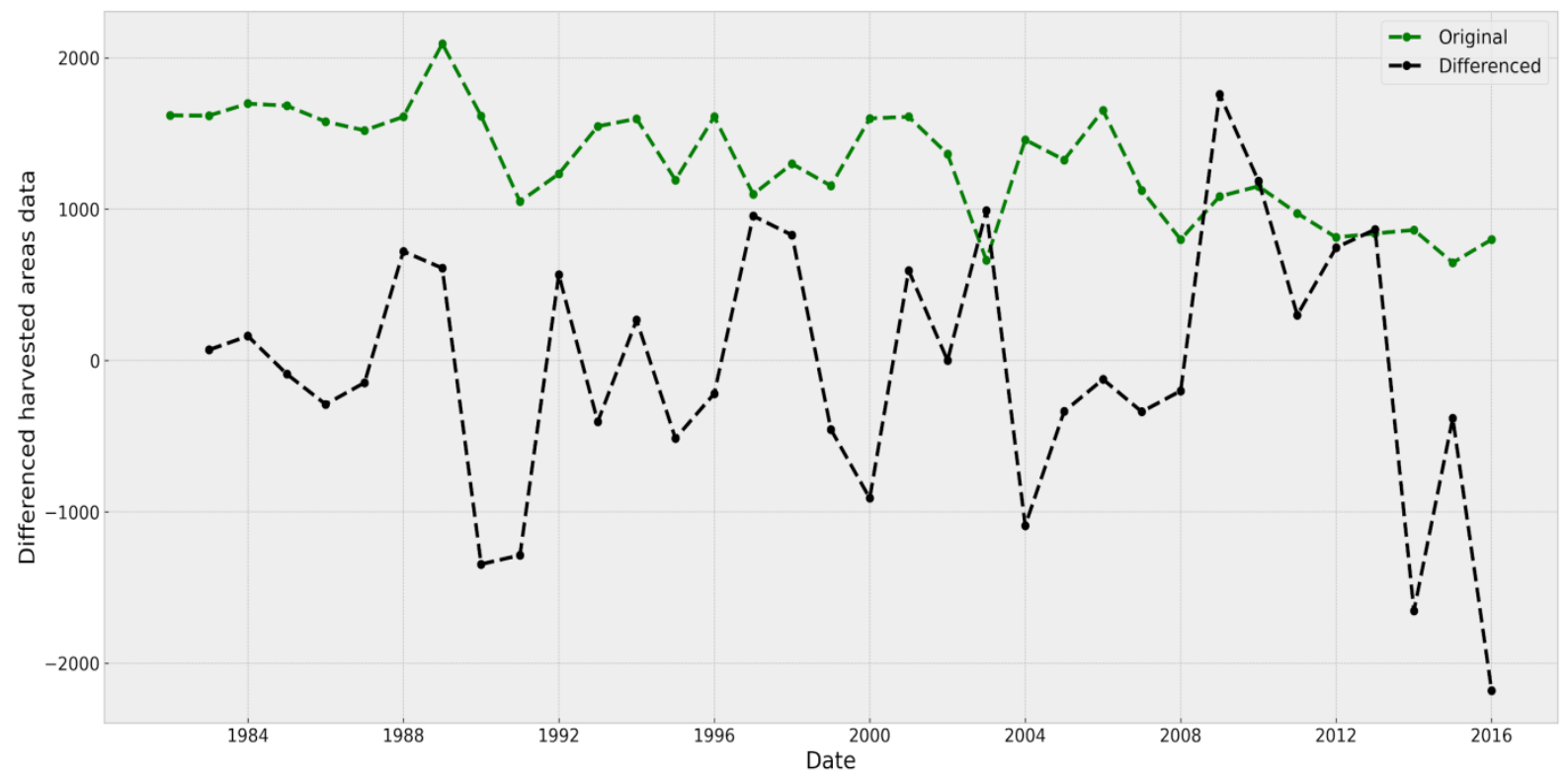




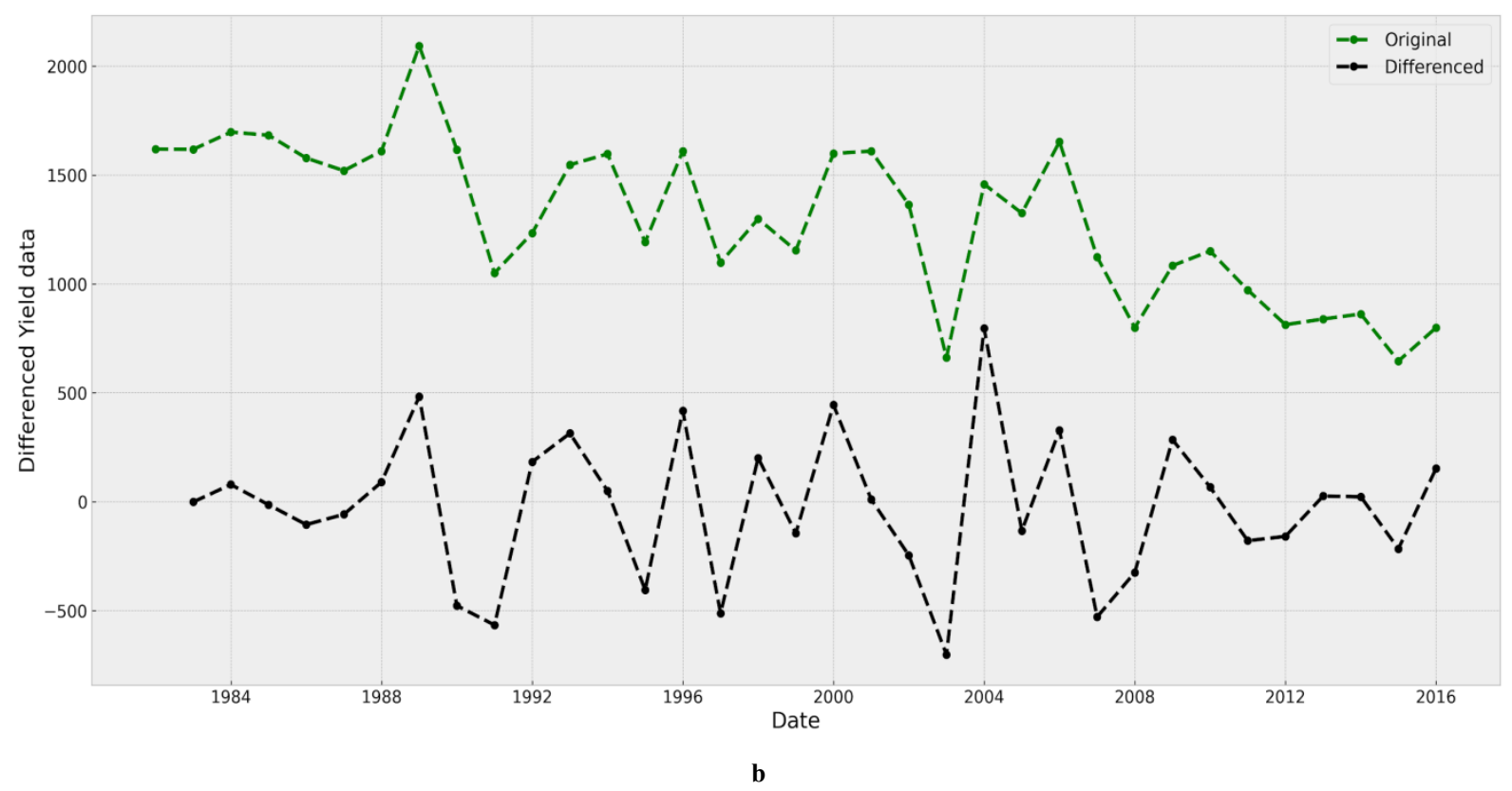

Figure 3. First order differencing; a harvested area, b yields

Table 3. ADF test results for harvested area and yield series after differencing

\begin{tabular}{|c|c|c|}
\hline \multicolumn{3}{|c|}{ Augmented Dickey-Fuller } \\
\hline Test Results & Area & Yields \\
\hline ADF Test Statistic & -4.33 & -5.57 \\
\hline P-Value & 0.000397 & 0.000002 \\
\hline Lags Used & 0.00 & 3.00 \\
\hline Critical Value (5\%) & -2.95 & -2.96 \\
\hline The time series is stationary & True & True \\
\hline
\end{tabular}

The ADF test was repeated on the results to check whether the times series were adjusted as stationary series that could be used for further analysis (Table 3 ).
The series have been made stationary for the future model.

\subsubsection{Patterns in the time series}

The time series reveals trends and seasonality in the monthly climate parameters (minimum and maximum temperature and precipitation) while the annual climate parameters do not have any seasonality. Figure 4 shows the classical decomposition of the monthly time series. It is obvious that the monthly series have seasonality. There is no trend in the minimum temperature and the rainfall but there is an increasing trend in the maximum temperature with a very small magnitude. 

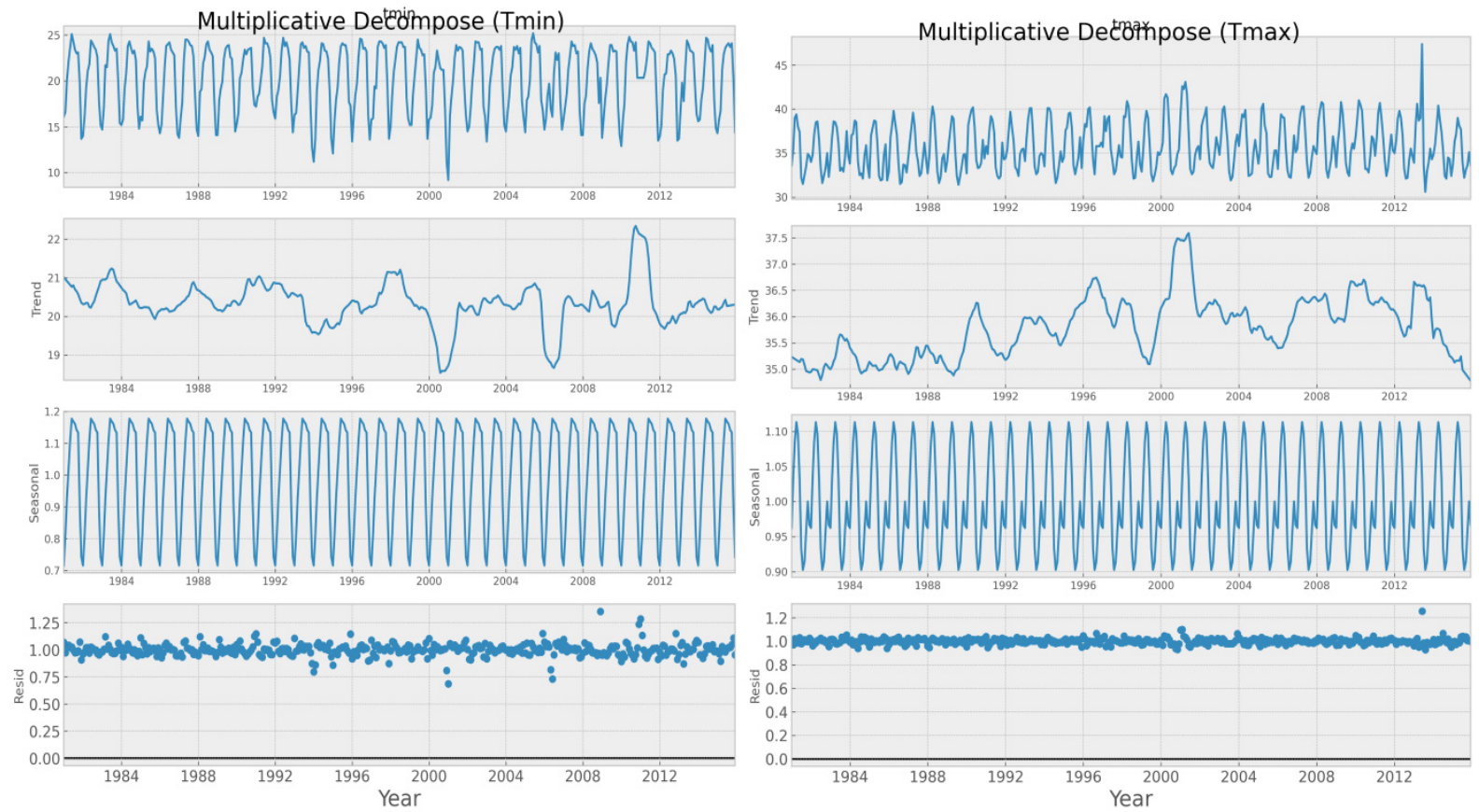

a)

b)
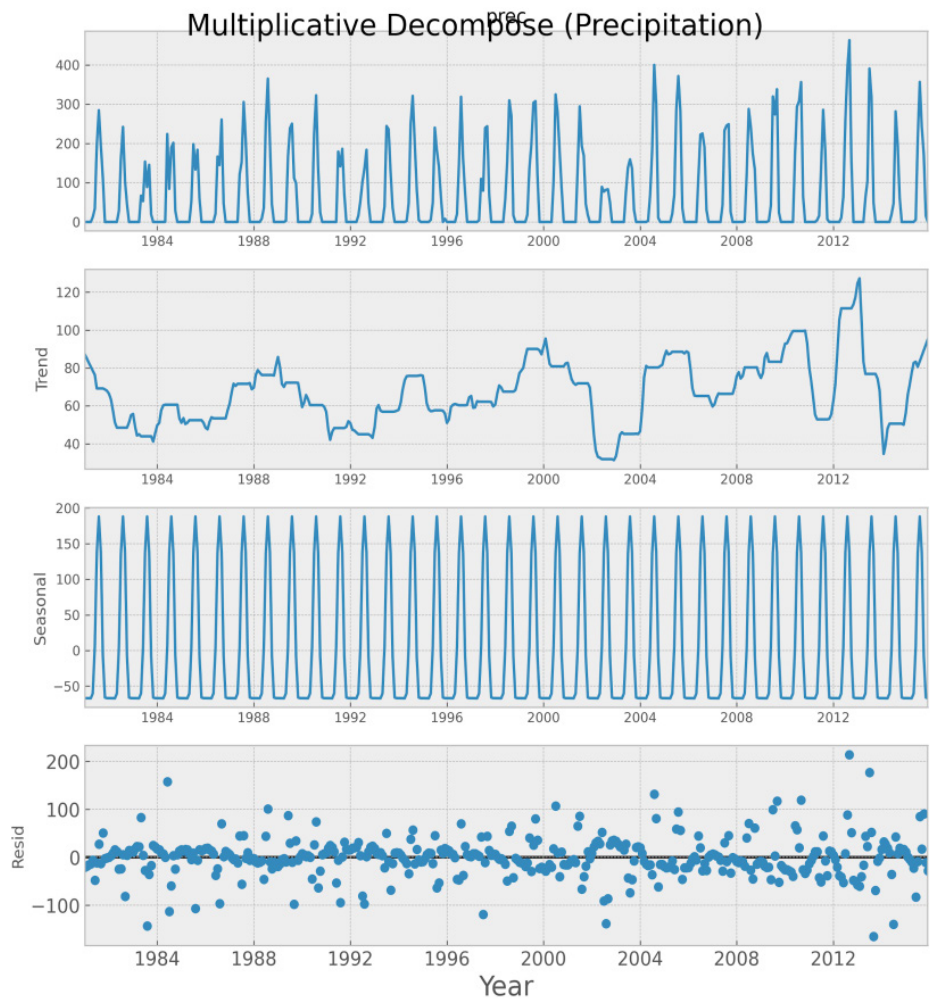

c)

Figure 4. Decomposition of the monthly climatic parameter series; a) minimum temperature, b) maximum temperature, c) rainfall 


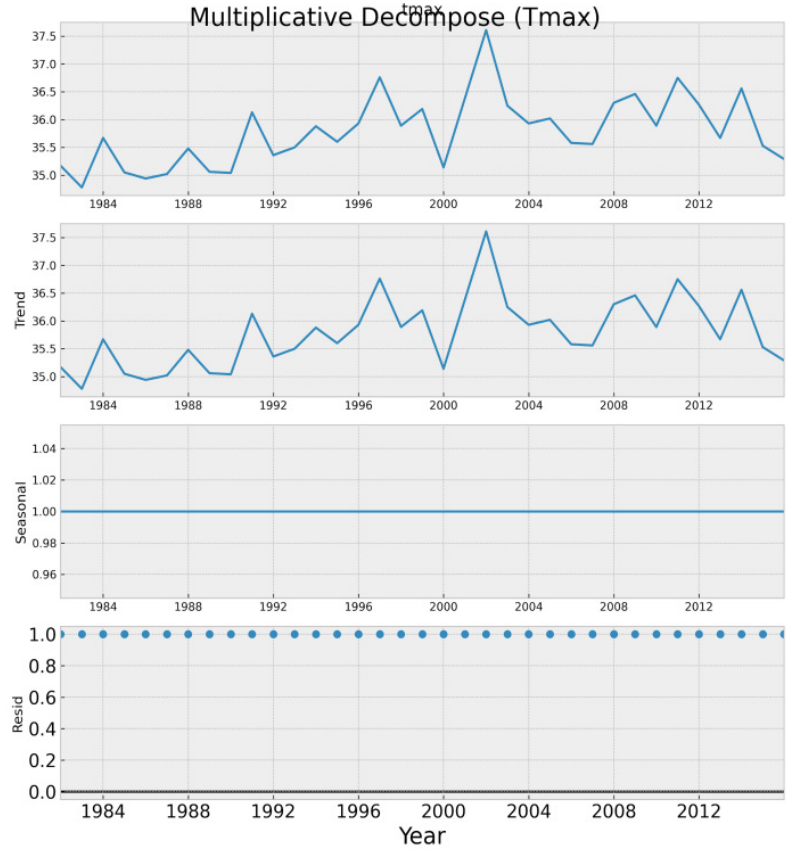

a)
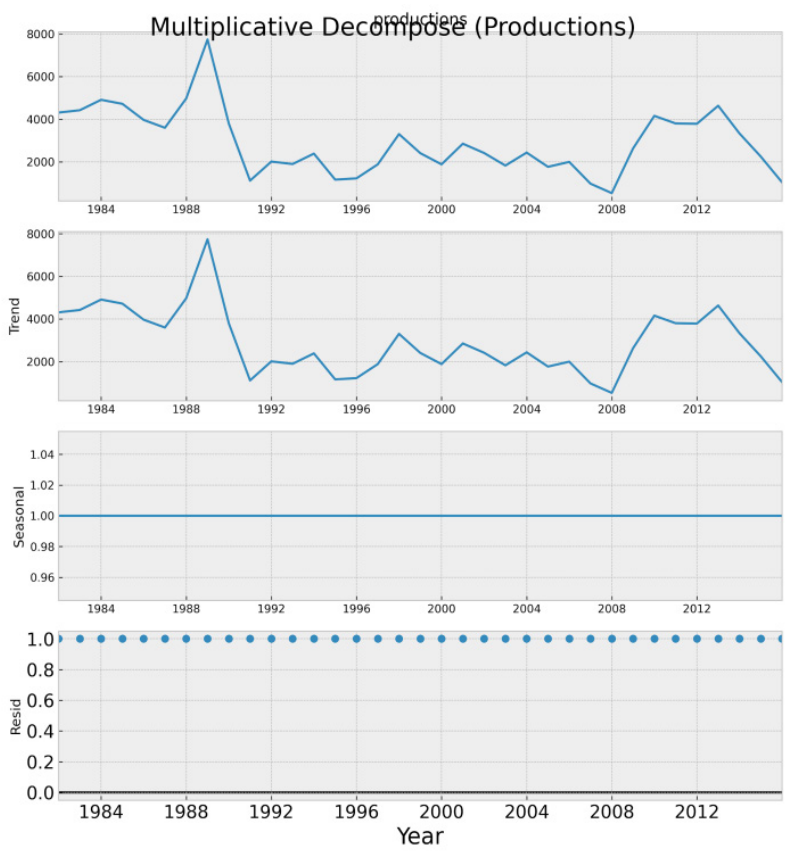

c)
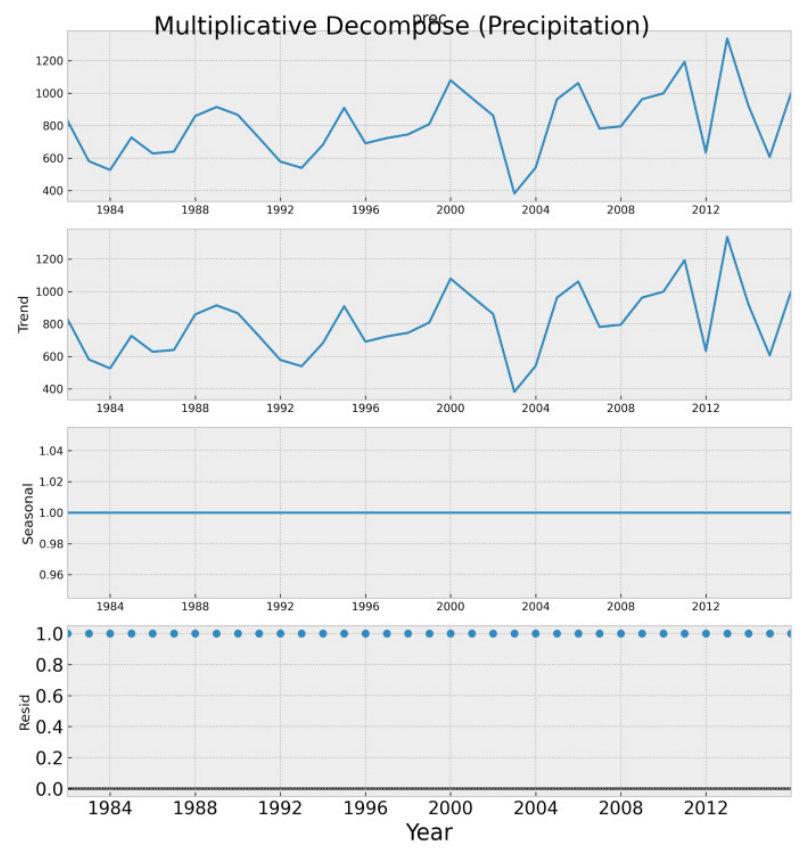

b)
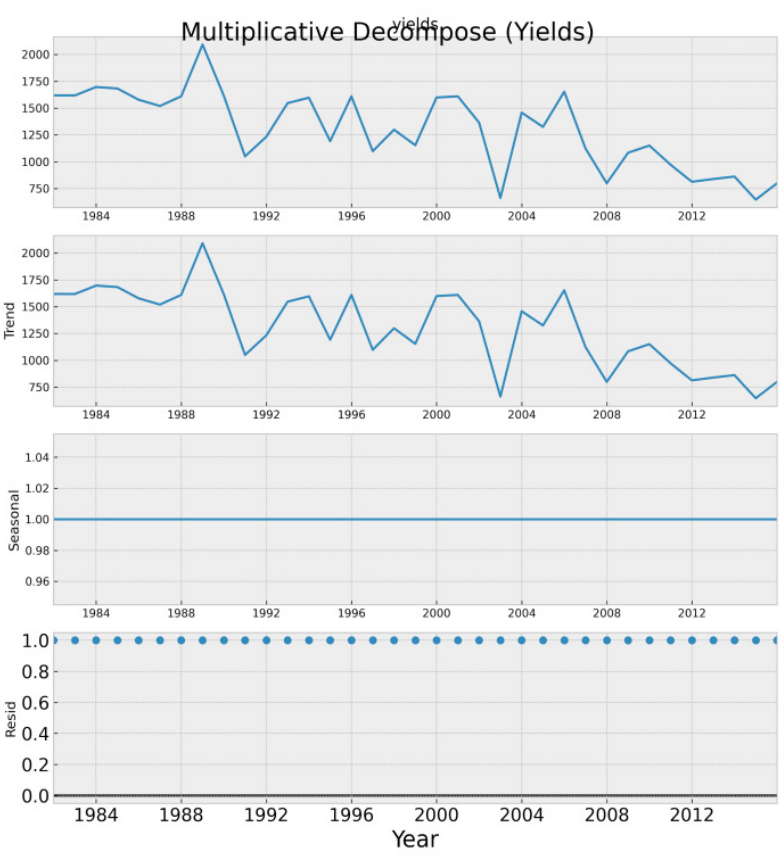

d)

Figure 5. Decomposition of the annual series; a) maximum temperature, b) rainfall, c) rice production, d) rice yield

The annual series do not have any seasonal component. The seasonal plot shows 0 and remains the same all year. Figure 5 shows the annual patterns of the climatic parameters and the rice cultivation in the LRR. The same pattern was observed in all the annual series. There is no trend in the annual series such as the minimum temperature, rice production and harvested area. There is an increasing trend in the maximum temperature and precipitation with a relatively high magnitude (slope $=9.581$ ). The rice yields have a decreasing trend with a high magnitude (slope $=$
-25.57). The yields' trend has been decreasing in the Figure $5 \mathrm{~d}$ "trend" with rainfall increasing in the same period (2000 - 2015) in Figure 5b "trend".

An explanation to this phenomenon is first related to the decreasing harvested area, as well as the productions which have a link with the cultivated area. The cultivated area is decreasing. This could also be due to the existence of other factors (cultivation practices, land tenure and conflicts, natural disasters, etc.) which in fact have an effect on the yield. The result corroborates Sonko et al. (2019) study in 
the region where findings showed yield decrease even though rainfall increases. Such results indicate that rice yields do not only depend on rainfall, but also on other factors that include, non-climate variables such as rice cultivation practices (Sonko et al., 2019; NRDS, 2014). Other studies have shown that continuous cultivation of irrigated rice, where the soil is maintained in anaerobic conditions for prolonged periods, does result in decreased yield (Pulver \& Nguyen 1999). Another possible factor is sea-level rise (Bagbohouna et al., 2018; NAPA, 2007; Webb, 1992) and the rainy season that becomes shorter, abnormal distribution of rainfall during the rainy season in the country (Fatajo, 2010). It has been reported that The Gambia faces sea-level rise as a result of global warming (UNEP, 2000) which may affect coastal rice-growing ecology in The Gambia (Clark et al., 2016; Fatajo, 2010; Njie, 2002; Webb, 1992). Since the rice cultivated by farmers are not saline tolerant and the overall rice farmers' adaptive responses to climate change risks, especially saline-water intrusion in the region are deficient (Bagbohouna et al., 2018; Webb, 1992), it is more likely to see decline in rice yields (Figure 6a).

The harvested area and the production showed together similar patterns and seem to have a good correlation in the two variables (Figure 6b). The yield (yield is a measurement of the amount of agricultural production harvested per unit of land area) decreased from 1985 to 1995 and increased from 2008. The production has increased from 2011 to change the pattern of the evolution from lower to higher values. At the same period, the maximum and the minimum temperatures exhibited an increase as well as rainfall, but the yield continued to decrease to even lower records changing the evolution pattern with the rainfall from higher to lower values. The decreasing trend of the yield confirms the decomposition trend component of the yield in Figure $6 \mathrm{~b}$.

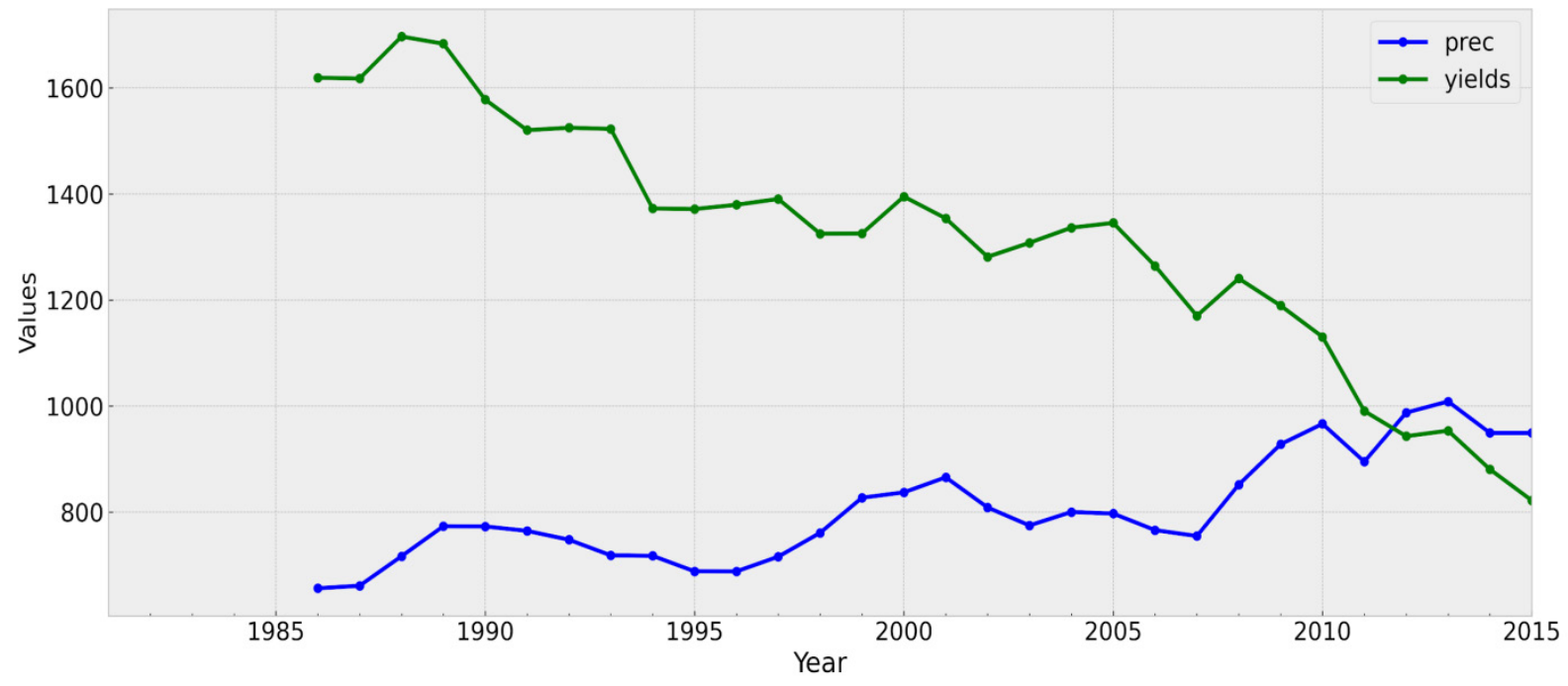

a)

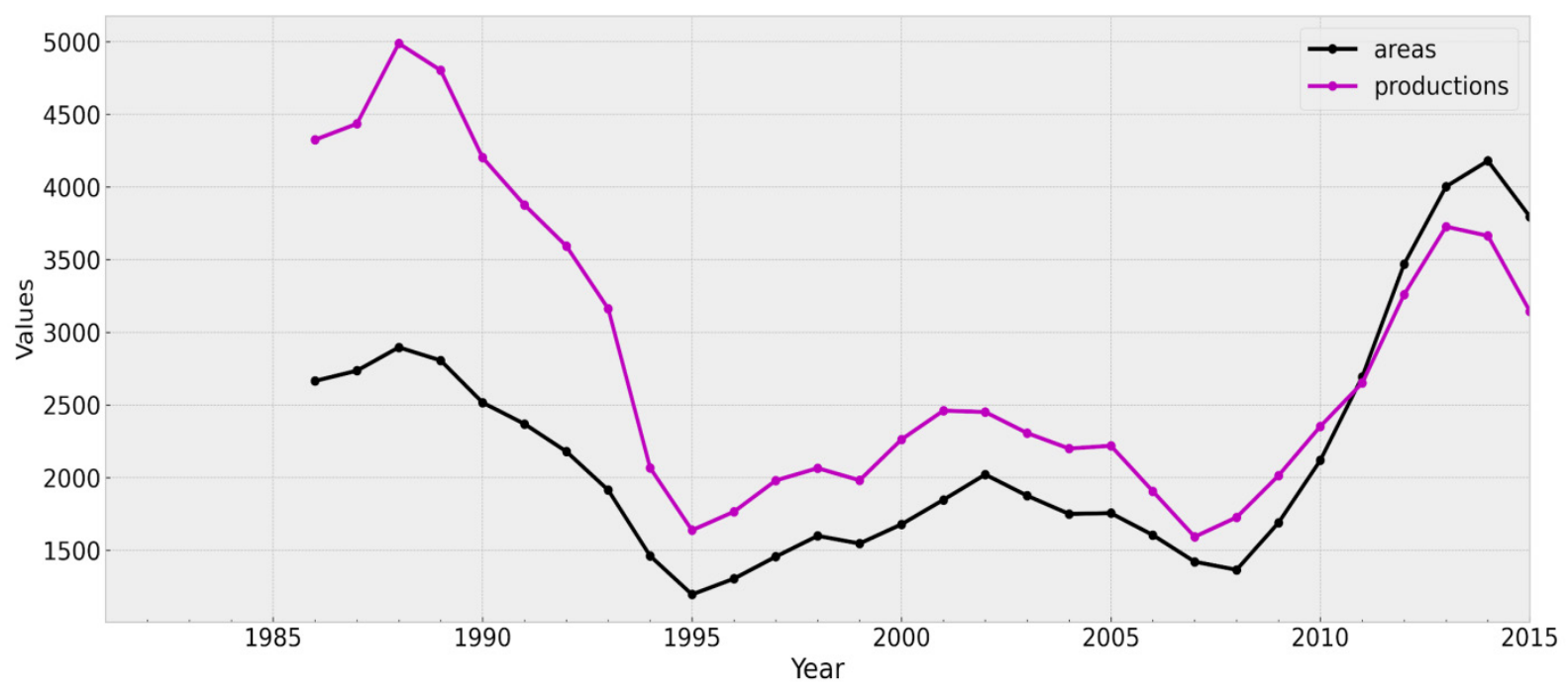

b)

Figure 6. Combination of annual series trends: a rainfall and yield; b harvested area and production 


\subsection{Linear Regression Model Results}

The autocorrelation and partial autocorrelation were first performed on annual data only.

\subsubsection{Correlation and Autocorrelation}

Figure 7 shows the regression lines at $95 \%$ of confidence interval of yields and production variables. Rainfall has very poor correlation with yields, as discussed previously
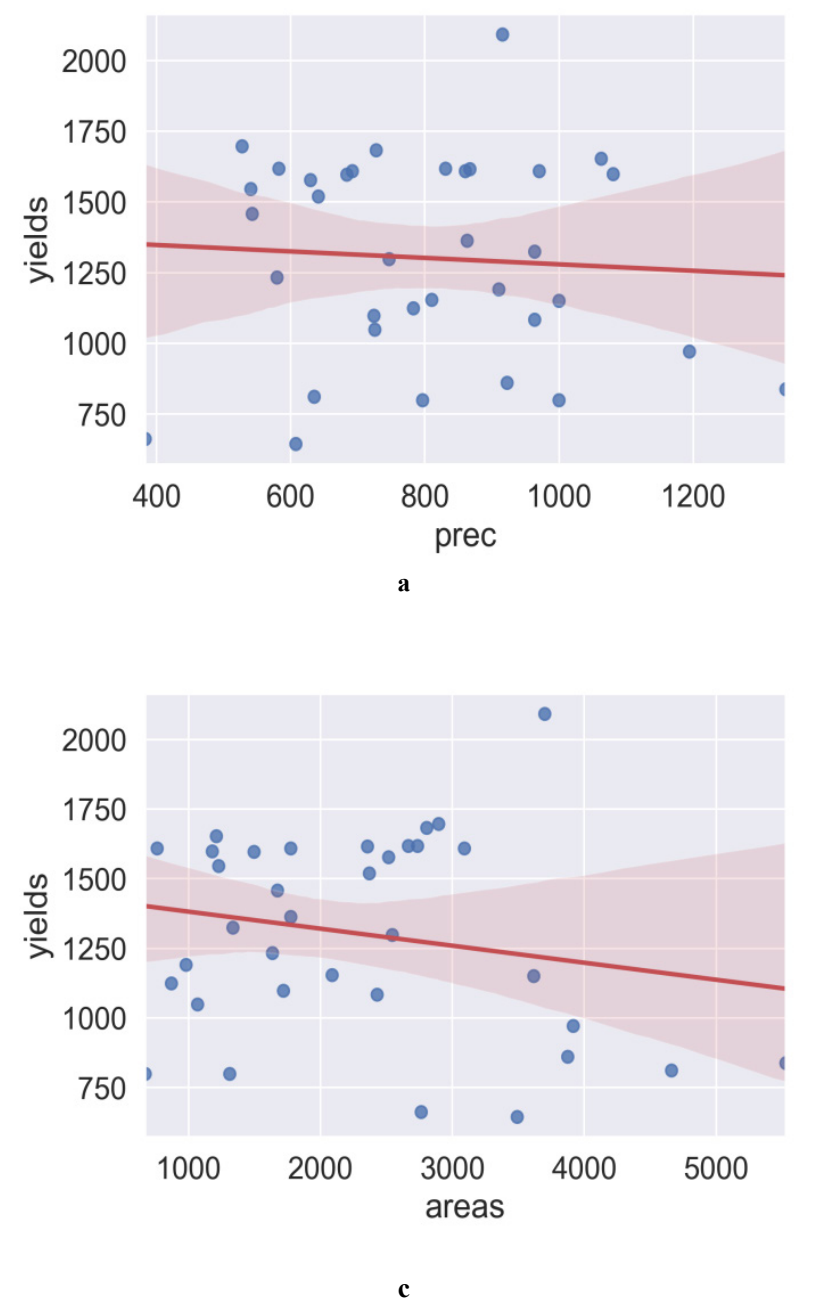

in the comparison plots. Yields, harvested areas and production in Figure $7 \mathrm{~b}, 7 \mathrm{c}$ and $7 \mathrm{~d}$ are rather well correlated to each other showing them as being the first parameters to take into account when analysing rice production using these series of data. Figure 8 presents the heatmap of correlation values with good correlation of the rice parameters between themselves and the poor correlation with the climatic parameters, especially the rainfall for the annual series.
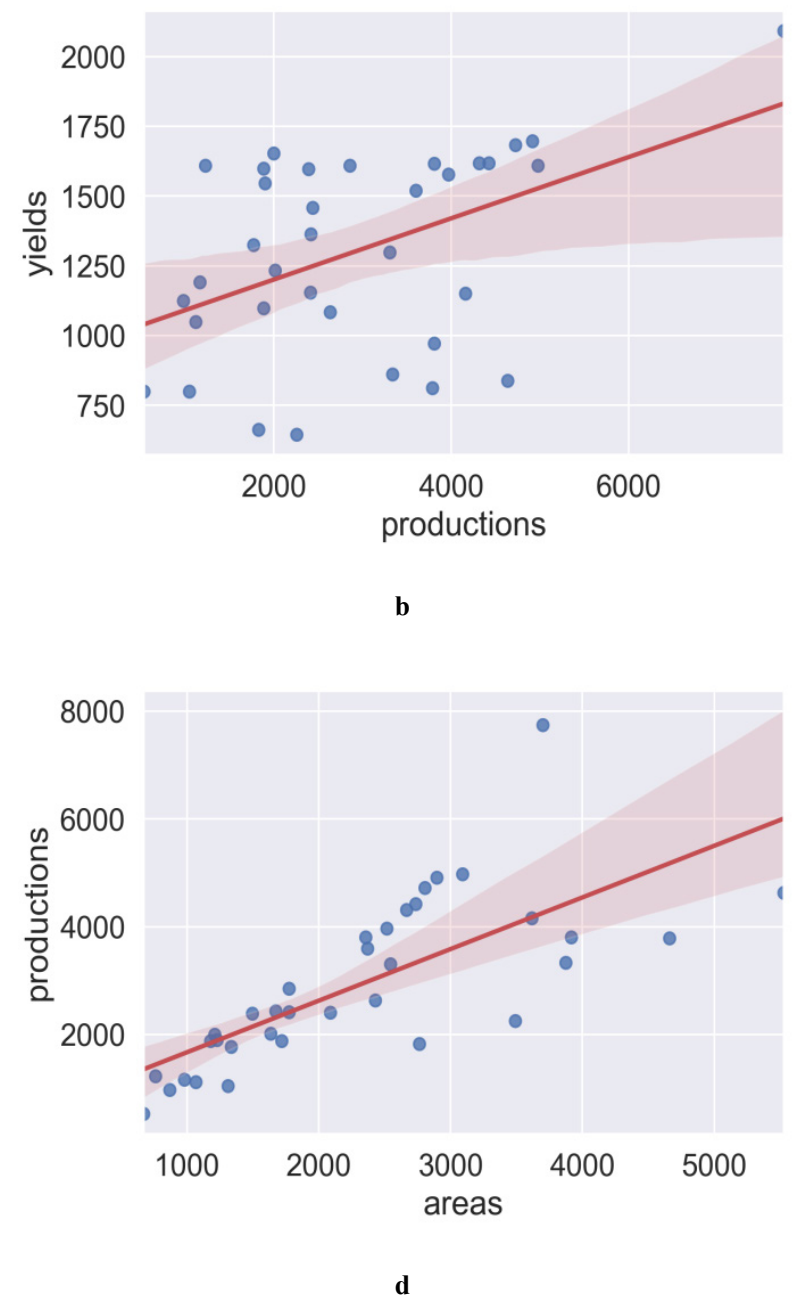

Figure 7. Correlation tendencies for yield, rainfall, areas and production with their regression line at $95 \%$ confidence. 


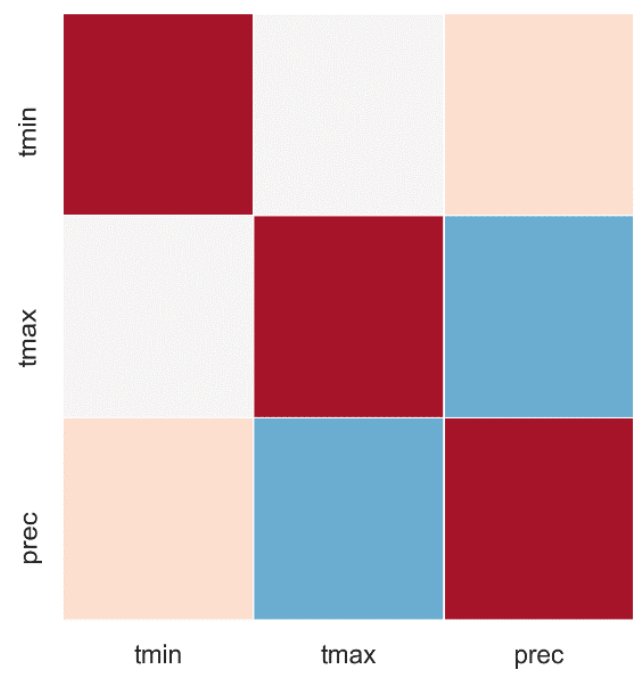

a)

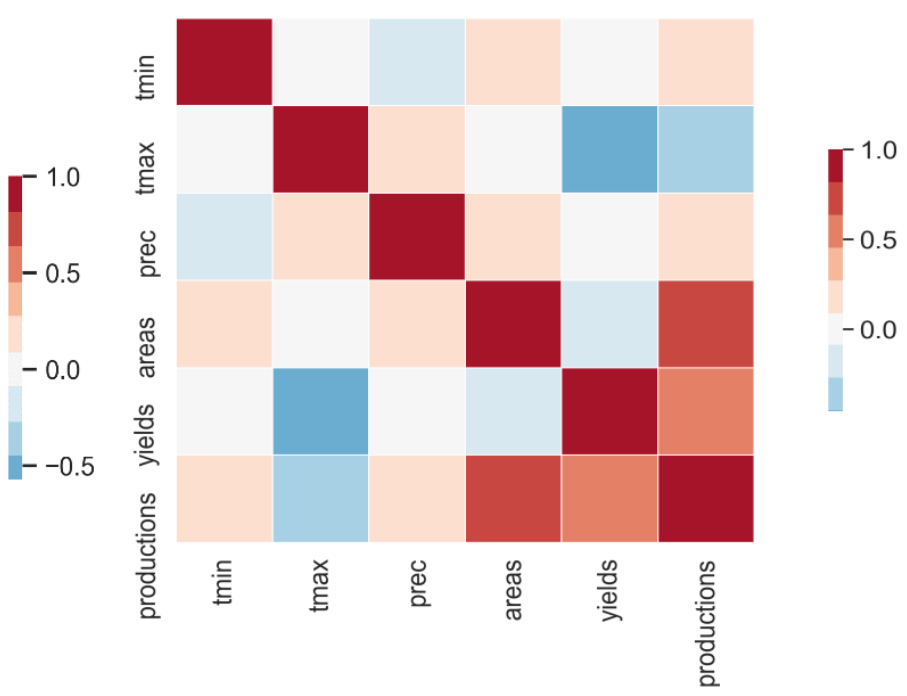

b)

Figure 8. Correlation heatmap for the monthly (a) and annual (b) parameters

The monthly series revealed high autocorrelation (climate parameters), meaning that values of each parameter within its own time series data are related to each other. Thus, there exists a relation between one variable current and previous value in each of the time series. There is high autocorrelation in the monthly series, making them serially correlated as well. The annual series climatic variables' autocorrelation and partial autocorrelation are shown in Figure 9, they were not serially correlated. The absence of autocorrelation between values is statistically significant (in the defined confidence interval). The lag values are very low, and they are all in the confidence interval (grey limit on both sides of the 0 value). This reveals that the annual climatic parameters are statistically not serially correlated.
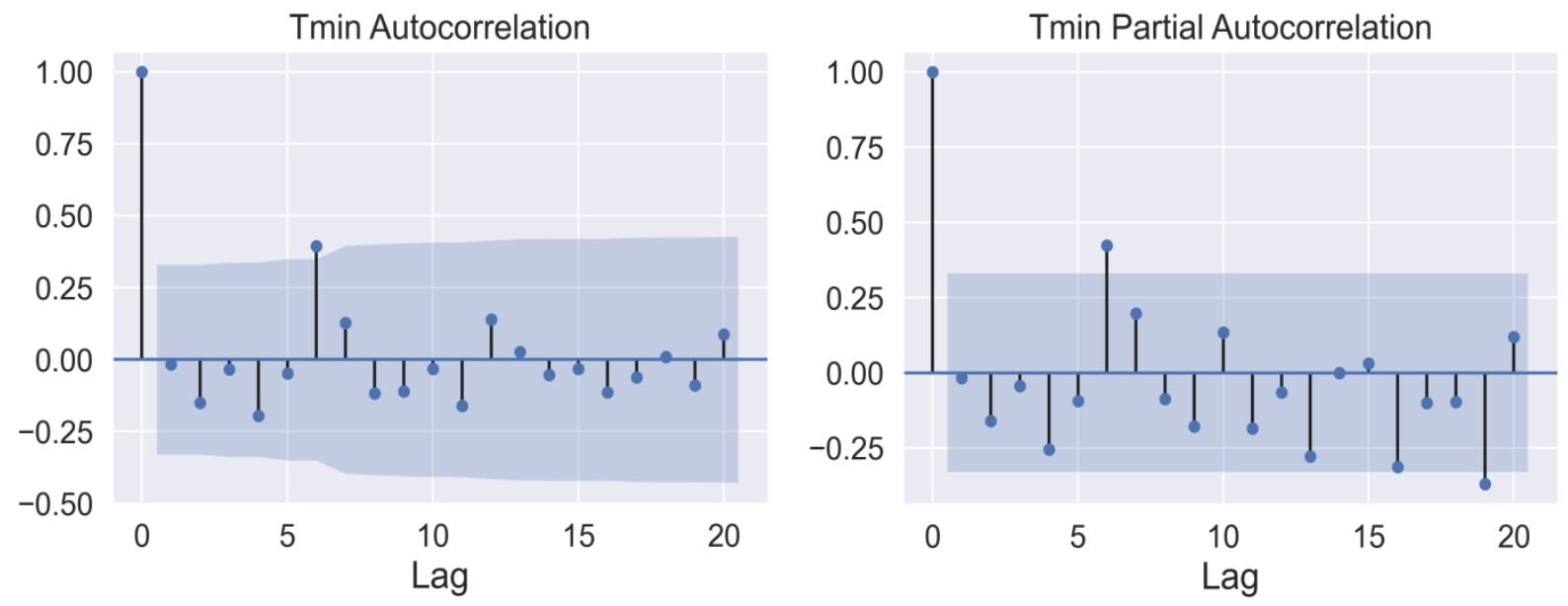

a) 

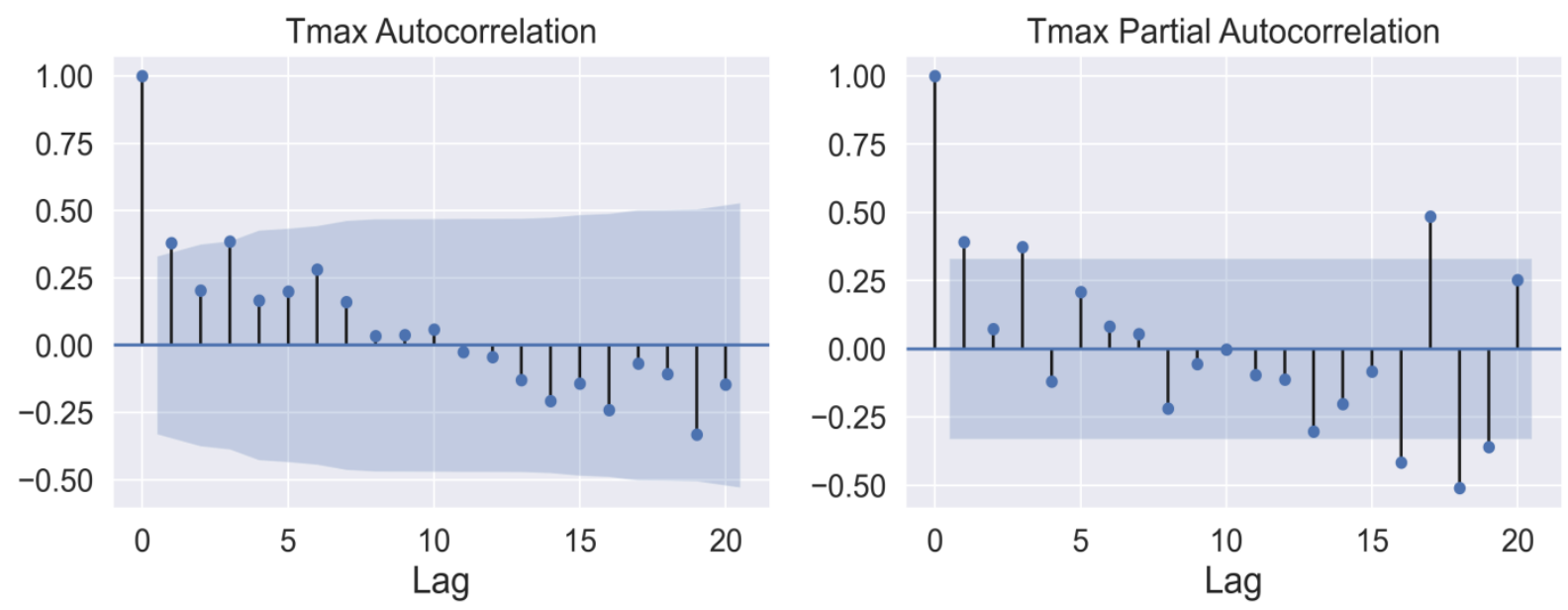

b)
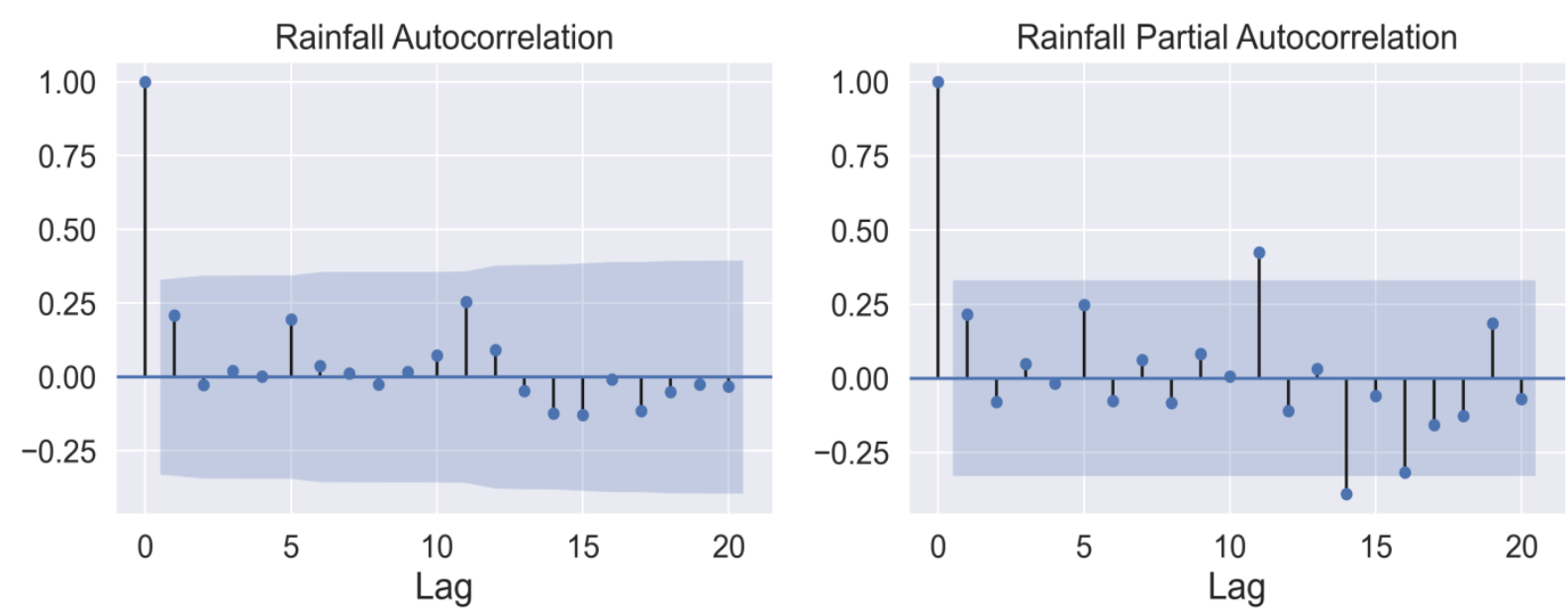

c)

Figure 9. ACF (left panel) and PACF (right panel) of annual climate parameters: a Tmin, b Tmax, $\mathbf{c}$ Rainfall

The Autocorrelation Function (ACF) and Partial Autocorrelation Function (PACF) were computed on rice production variables using the first order difference values for area and yield in order to determine the model parameters to use (Figure 10 and 11). It is observed that the entire pattern shows the same thing, leading to a unique and commonly accepted conclusion; the lag where the line crosses the confidence interval both on the positive and the negative sides is the lag considered for the model parameter. To choose the Autoregressive AR(p) parameter, the lag value where the PACF line in the chart crosses the upper confidence interval for the first time is considered, $\mathrm{p}=1, \mathrm{AR}(1)$, here from almost all the PACF plots. An AR(1) autoregressive process is one in which the current value is based on the immediately preceding value. For the Moving Average MA(q) parameter, the lag value where the ACF line crosses the upper confidence interval for the first time, $\mathrm{q}=1$ or 2 . The $\operatorname{VARMA}(\mathrm{p}, \mathrm{q})$ model (where $\mathrm{p}$ is the number of lag observations included in the model, also called the lag order and $\mathrm{q}$ the size of the moving average window, also called the order of moving average for AR and MA processes respectively) according to the ACF and PACF results: MODEL $(1,1)$ or MODEL $(1,2)$ where $(1,1)$ and $(1,2)$ are the orders of the VARMA model. The two were tested and checked for performance. 


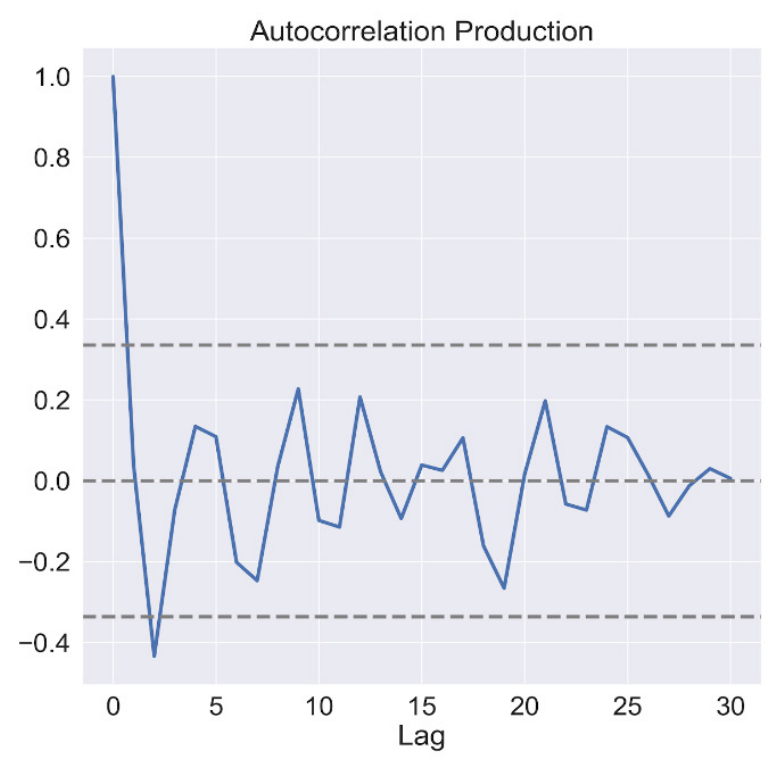

a)

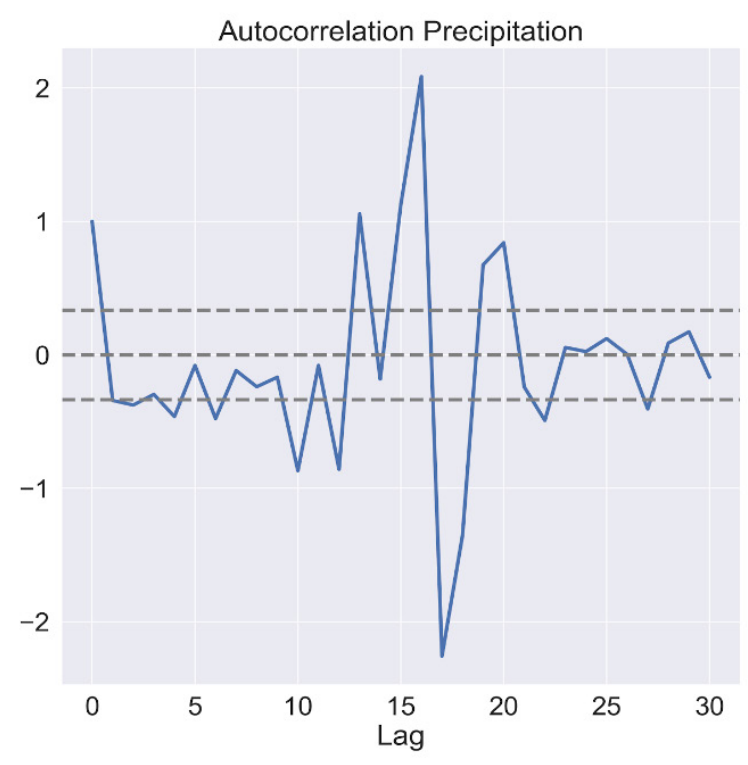

b)

Figure 10. ACF on first order Difference: a) production and b) rainfall
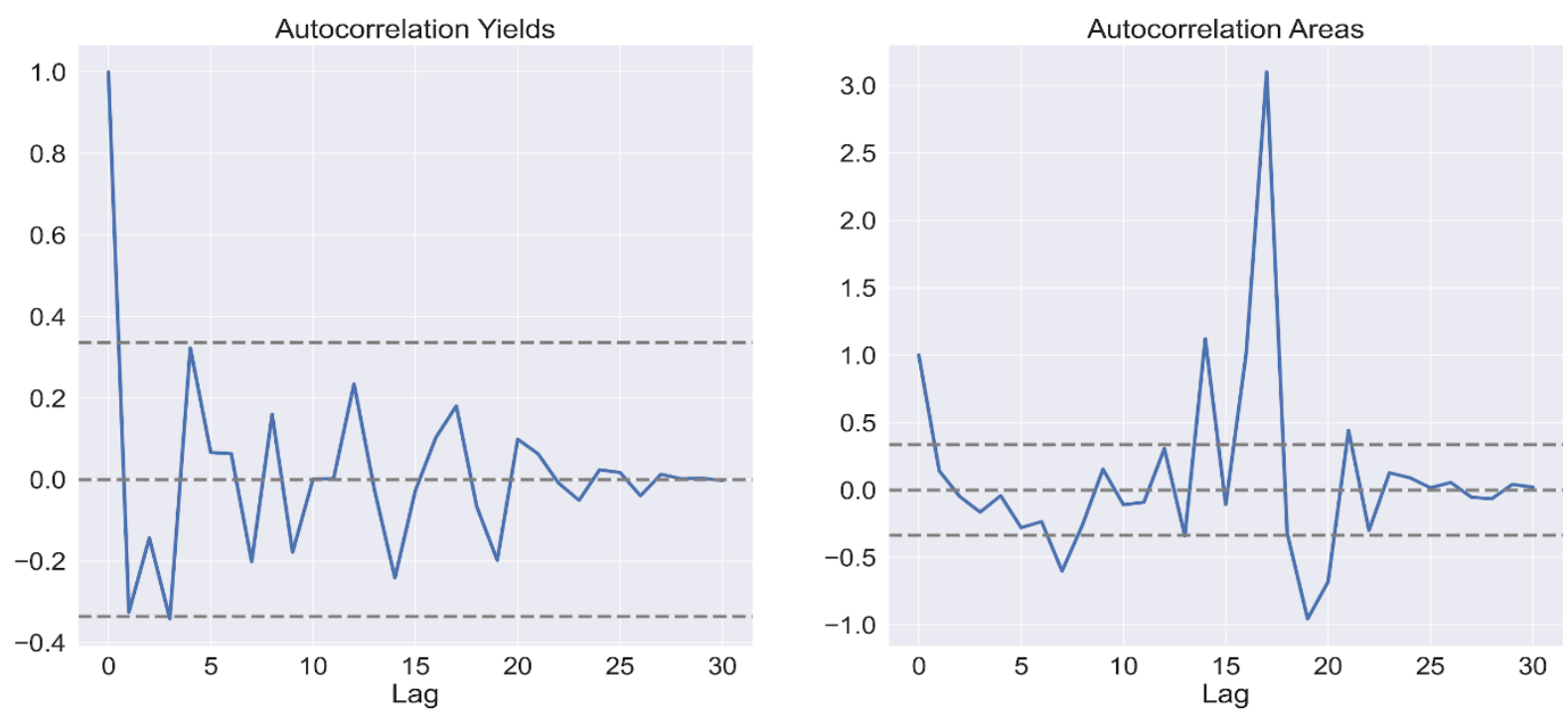

Figure 11. ACF on first order Difference: a) yield, b) area

Table 4. Multiple Linear Regression Results on monthly series (climate parameters)

\begin{tabular}{|c|c|c|c|c|c|c|}
\hline \multicolumn{2}{|c|}{ Dependent Variable: } & \multicolumn{2}{|c|}{ Rainfall } & \multicolumn{2}{|c|}{ R-squared: } & 0.618 \\
\hline \multicolumn{2}{|c|}{ Model: } & \multicolumn{2}{|c|}{ OLS } & \multicolumn{2}{|c|}{ Adj. R-squared: } & 0.62 \\
\hline \multicolumn{2}{|c|}{ Method: } & \multicolumn{2}{|c|}{ Least Squares } & \multicolumn{2}{|c|}{ F-statistic: } & 336.6 \\
\hline & & & & \multicolumn{2}{|c|}{ Prob (F-statistic): } & 0 \\
\hline \multicolumn{2}{|c|}{ Df Residuals: } & \multicolumn{2}{|c|}{417} & \multicolumn{2}{|c|}{ Log-Likelihood: } & -2340.9 \\
\hline \multicolumn{2}{|c|}{ Df Model: } & \multirow{2}{*}{\multicolumn{2}{|c|}{$\frac{2}{\text { Non-robust }}$}} & \multicolumn{2}{|c|}{ AIC: } & 4688 \\
\hline \multicolumn{2}{|c|}{ Covariance Type: } & & & \multicolumn{2}{|c|}{ BIC: } & 4700 \\
\hline & coefficient & std err & $\mathbf{T}$ & $\mathbf{P}>|\mathbf{t}|$ & {$[0.025$} & $0.975]$ \\
\hline Intercept & 519.2 & 47.1 & 11.03 & 0.000 & 426.63 & 611.78 \\
\hline Tmax & -20.73 & 1.15 & -17.99 & 0.000 & -23 & -18.47 \\
\hline Tmin & 14.25 & 0.88 & 16.25 & 0.000 & 12.52 & 15.97 \\
\hline \multicolumn{2}{|c|}{ Omnibus: } & \multicolumn{2}{|c|}{68.860} & \multicolumn{2}{|c|}{ Durbin-Watson: } & 1.216 \\
\hline \multicolumn{2}{|c|}{ Prob(Omnibus): } & \multicolumn{2}{|l|}{0} & \multicolumn{2}{|c|}{ Jarque-Bera (JB): } & 118.57 \\
\hline \multicolumn{2}{|c|}{ Skew: } & \multicolumn{2}{|c|}{0.96} & \multicolumn{2}{|c|}{$\operatorname{Prob}(\mathrm{JB})$ : } & 0 \\
\hline \multicolumn{2}{|c|}{ Kurtosis: } & \multicolumn{2}{|c|}{4.75} & \multicolumn{2}{|c|}{ Cond. No. } & 623 \\
\hline
\end{tabular}




\subsubsection{Multi-linear Regression Analysis}

The analysis of monthly climate variations on temperatures and rainfall was performed using the Ordinary Least Square (OLS) method, a widely known and used linear regression shows correlation between variables and the possible interrelationship that exists between the dependent and independent variables as in Table 4.

The value of adjusted R-squared (0.62) indicates that the overall model fits well, meaning that this model explains $62 \%$ of the variance in the dependent variable (rainfall). The coefficient also unwrapped the positive (14.25) association between the minimum temperature and precipitation which means that rainfall increases with a unit increase in minimum temperature by $14 \mathrm{~mm}$ assuming that the maximum temperature remains constant. However, rainfall decreases (coefficient $=-20.73$ ) with a unit increase in maximum temperature by $20 \mathrm{~mm}$ (assuming minimum temperature is constant).

A multi-linear regression was performed using the same OLS simple regression method to identify the effect of climate variation on rice production in the region using annual data as the rice data is annual, the results are presented in Table 5. The model showed that the multiple variables poorly explain $(12 \%)$ the rice production in the LRR. The p-values revealed that rainfall and minimum temperature results are statistically non-significant in determining production of rice in the region while the maximum temperature accepts the changes with the dependent variable; but the model does not explain the variance in the dependent rice production.

The coefficient further indicates that rainfall and minimum temperature could increase production of rice, whereas maximum temperature will decrease it by $860 \mathrm{ha} / \mathrm{t}$ with a unit increase. This means that an increase in average maximum temperature will further reduce the production of rice. This indicates that any variation in the rainfall affects rice production but the data showed that this result is insignificant (Wu et al., 2017). In reality, high temperature is a disadvantage to rice production (Sridevi and Chellamuthu 2015; Peng et al., 2004). One is tempted to say that, in case annual average temperature is good for rice growth, a change in the temperature may slightly impact the reliability of rice production. Oort \& Zwart (2017) explained it in the terms of decline in rice production results from high temperatures which induce reduction of photosynthesis in the rice stalks.

Table 5. Multiple Linear Regression Results (rice Production and climate parameters)

\begin{tabular}{|c|c|c|c|c|c|c|}
\hline \multicolumn{2}{|c|}{ Dep. Variable: } & \multicolumn{2}{|r|}{ Productions } & \multicolumn{2}{|c|}{ R-squared: } & 0.197 \\
\hline \multicolumn{2}{|c|}{ Model: } & & OLS & \multicolumn{2}{|c|}{ Adj. R-squared: } & 0.12 \\
\hline \multicolumn{2}{|c|}{ Method: } & & Least Squares & \multicolumn{2}{|c|}{ F-statistic: } & 2.54 \\
\hline \multicolumn{2}{|c|}{ No. Observations: } & & 35 & \multicolumn{2}{|c|}{ Prob (F-statistic): } & 0.07 \\
\hline \multicolumn{2}{|c|}{ Df Residuals: } & & 31 & \multicolumn{2}{|c|}{ Log-Likelihood: } & -301.76 \\
\hline \multicolumn{2}{|c|}{ Df Model: } & & 3 & \multicolumn{2}{|c|}{ AIC: } & 611.5 \\
\hline \multicolumn{2}{|c|}{ Covariance Type: } & & Non robust & \multicolumn{2}{|c|}{ BIC: } & 617.7 \\
\hline & coefficient & std err & $\mathbf{T}$ & $\mathbf{P}>|\mathbf{t}|$ & {$[0.025$} & $0.975]$ \\
\hline Intercept & 17840 & 16700 & 1.07 & 0.29 & -16200 & 51900 \\
\hline prec & 1.46 & 1.21 & 1.21 & 0.24 & -1 & 3.93 \\
\hline $\operatorname{tmax}$ & -860.97 & 395.56 & -2.18 & 0.04 & -1667.72 & -54.22 \\
\hline tmin & 723.87 & 451.62 & 1.6 & 0.12 & -197.22 & 1644.96 \\
\hline \multicolumn{2}{|c|}{ Omnibus: } & 1.593 & \multicolumn{3}{|c|}{ Durbin-Watson: } & 0.956 \\
\hline \multicolumn{2}{|c|}{ Prob(Omnibus): } & 0.45 & \multicolumn{3}{|c|}{ Jarque-Bera (JB): } & 0.74 \\
\hline \multicolumn{2}{|c|}{ Skew: } & 0.31 & \multicolumn{3}{|c|}{$\operatorname{Prob}(\mathrm{JB})$ : } & 0.69 \\
\hline \multicolumn{2}{|c|}{ Kurtosis: } & 3.34 & & \multicolumn{2}{|c|}{ Cond. No. } & 57300 \\
\hline
\end{tabular}


Table 6. Multiple Linear Regression Results (rice Yields and climate parameters)

\begin{tabular}{|c|c|c|c|c|c|c|}
\hline \multicolumn{2}{|c|}{ Dep. Variable: } & \multicolumn{2}{|c|}{ Yields } & \multicolumn{2}{|c|}{ R-squared: } & 0.209 \\
\hline \multicolumn{2}{|c|}{ Model: } & \multicolumn{2}{|c|}{ OLS } & \multicolumn{2}{|c|}{ Adj. R-squared: } & 0.13 \\
\hline \multicolumn{2}{|c|}{ Method: } & \multicolumn{2}{|c|}{ Least Squares } & \multicolumn{2}{|c|}{ F-statistic: } & 2.73 \\
\hline \multicolumn{2}{|c|}{ No. Observations: } & \multicolumn{2}{|c|}{35} & \multicolumn{2}{|c|}{ Prob (F-statistic): } & 0.06 \\
\hline \multicolumn{2}{|c|}{ Df Residuals: } & \multicolumn{2}{|c|}{31} & \multicolumn{2}{|c|}{ Log-Likelihood: } & -250.92 \\
\hline \multicolumn{2}{|c|}{ Df Model: } & \multicolumn{2}{|c|}{3} & \multicolumn{2}{|c|}{ AIC: } & 509.8 \\
\hline \multicolumn{2}{|c|}{ Covariance Type: } & \multicolumn{2}{|c|}{ Non robust } & \multicolumn{2}{|c|}{ BIC: } & 516.1 \\
\hline & Coefficient & std err & $\mathbf{T}$ & $\mathbf{P}>|\mathbf{t}|$ & {$[0.025$} & $0.975]$ \\
\hline Intercept & 10320 & 3903.44 & 2.65 & 0.01 & 2362.19 & 18300 \\
\hline prec & 0 & 0.28 & 0.02 & 0.99 & -0.57 & 0.58 \\
\hline $\operatorname{tmax}$ & -261.97 & 92.53 & -2.83 & 0.01 & -450.69 & -73.24 \\
\hline $\operatorname{tmin}$ & 17.23 & 105.65 & 0.16 & 0.87 & -198.24 & 232.71 \\
\hline \multicolumn{2}{|c|}{ Omnibus: } & \multicolumn{2}{|l|}{0.845} & \multicolumn{2}{|c|}{ Durbin-Watson: } & 1.144 \\
\hline \multicolumn{2}{|c|}{ Prob (Omnibus): } & \multicolumn{2}{|l|}{0.66} & \multicolumn{2}{|c|}{ Jarque-Bera (JB): } & 0.76 \\
\hline \multicolumn{2}{|c|}{ Skew: } & -0.34 & & $\mathrm{~b}(\mathrm{JB})$ & & 0.68 \\
\hline & & 2.73 & & nd. No. & & 57300 \\
\hline
\end{tabular}

Table 6 shows the contribution of the climate variables (rainfall, Tmax, Tmin) on rice yield as obtained from OLS regression. Rainfall does not influence the rice yield while minimum temperature shows a positive influence on the rice yields. The high $\mathrm{p}$-values of 0.99 and 0.87 respectively for rainfall and minimum temperature suggest that the changes that they could bring to the dependent variable (yield) are statistically insignificant; however maximum temperature reveals a low p-value of 0.01 and a negative coefficient of -261.97 which denotes a decrease in yield with a unit increase in maximum temperature assuming all the independent variables are constant. This result contradicts Peng et al. (2004) study which provides direct evidence of decreased rice yields from increased night-time temperature associated with global warming. In Welch et al. (2010), it is found that higher minimum temperature reduced yield, whereas higher maximum temperature raised it but there was no threshold in the maximum temperature value.

These results of the multilinear regression using OLS method showed in all that there is a relationship between temperature and precipitation but the overall significance is low (as for yield and precipitation, yield and minimum temperature and for production and precipitation, production and minimum temperature), meaning the changes are not statistically significant at $95 \%$ (alpha $=$ $0.05)$.

When all the variables are added to the model with previously dependent variables (yield and production), the model performs very well ( $93 \%$ of the data explain the rice production), but only the harvested area and the yields present significant changes and $85 \%$ of the data explain the rice yield with only harvested areas and productions showing significant changes. This shows that the rice production variables affect rice production in the Lower River Region more than the climate affects production.

\subsection{Statistical Prediction}

\subsubsection{The VARMA Model}

VARMA model does not necessarily ask if the variables have strong influence on each other with complete knowledge of the strength of the relations as could require structural models with simultaneous equations. The VARMA model with order $(1,1)$ was employed as parameter combinations. The ACF and PACF were applied to the first order difference of the series in order to determine the "p" and the "q" for the AR(p) and MA(q) models as parameters to the VARMA function in python as previously described. The selection of "p" was at the position of the lag value where the PACF chart crosses the upper confidence interval for the first time and the "q" position at the lag value where the ACF chart crosses the upper confidence interval for the first time. Table 10 showed the results concerning the model and its performance, considering the AIC (Akaike Information Criterion) and BIC (Bayesian Information Criterion) that are both penalized-likelihood criteria used to determine not only the performance but also the explanation of the model (BIC allows consistent estimation of the underlying data generating process). 
Table 7. VARMA model Results

\begin{tabular}{|c|c|c|c|c|}
\hline Variable: & $\begin{array}{c}\text { 'tmin', 'tmax', 'prec', 'areas', 'yields', } \\
\text { 'productions' }\end{array}$ & \multicolumn{2}{|c|}{ No. Observations: } & 35 \\
\hline Model: & $\operatorname{VARMA}(1,1)$ & \multicolumn{2}{|c|}{ Log Likelihood } & -1030.956 \\
\hline & + intercept & \multicolumn{2}{|l|}{ AIC } & 2259.912 \\
\hline \multirow{2}{*}{ Covariance Type: } & \multirow{2}{*}{ outer product of gradients (OPG) estimate } & \multicolumn{2}{|l|}{ BIC } & 2413.891 \\
\hline & & \multicolumn{2}{|c|}{ HQIC } & 2313.066 \\
\hline Ljung-Box (Q): & $30.61,23.68,27.62,28.92,19.09,32.07$ & Jarque-Bera (JB): & \multicolumn{2}{|c|}{$1.12,1.35,1.21,1.94,1.60,3.25$} \\
\hline $\operatorname{Prob}(Q):$ & $0.63,0.91,0.77,0.71,0.98,0.56$ & Prob (JB): & \multicolumn{2}{|c|}{$0.57,0.51,0.55,0.38,0.45,0.20$} \\
\hline Heteroskedasticity (H): & $2.32,1.54,2.13,0.98,1.40,0.60$ & Skew: & \multicolumn{2}{|c|}{$0.41,0.13,0.38,-0.25,0.44,0.26$} \\
\hline $\operatorname{Prob}(\mathrm{H})$ (two-sided): & $0.16,0.47,0.20,0.97,0.57,0.39$ & Kurtosis: & \multicolumn{2}{|c|}{$2.70,2.08,2.50,1.96,2.44,4.40$} \\
\hline
\end{tabular}
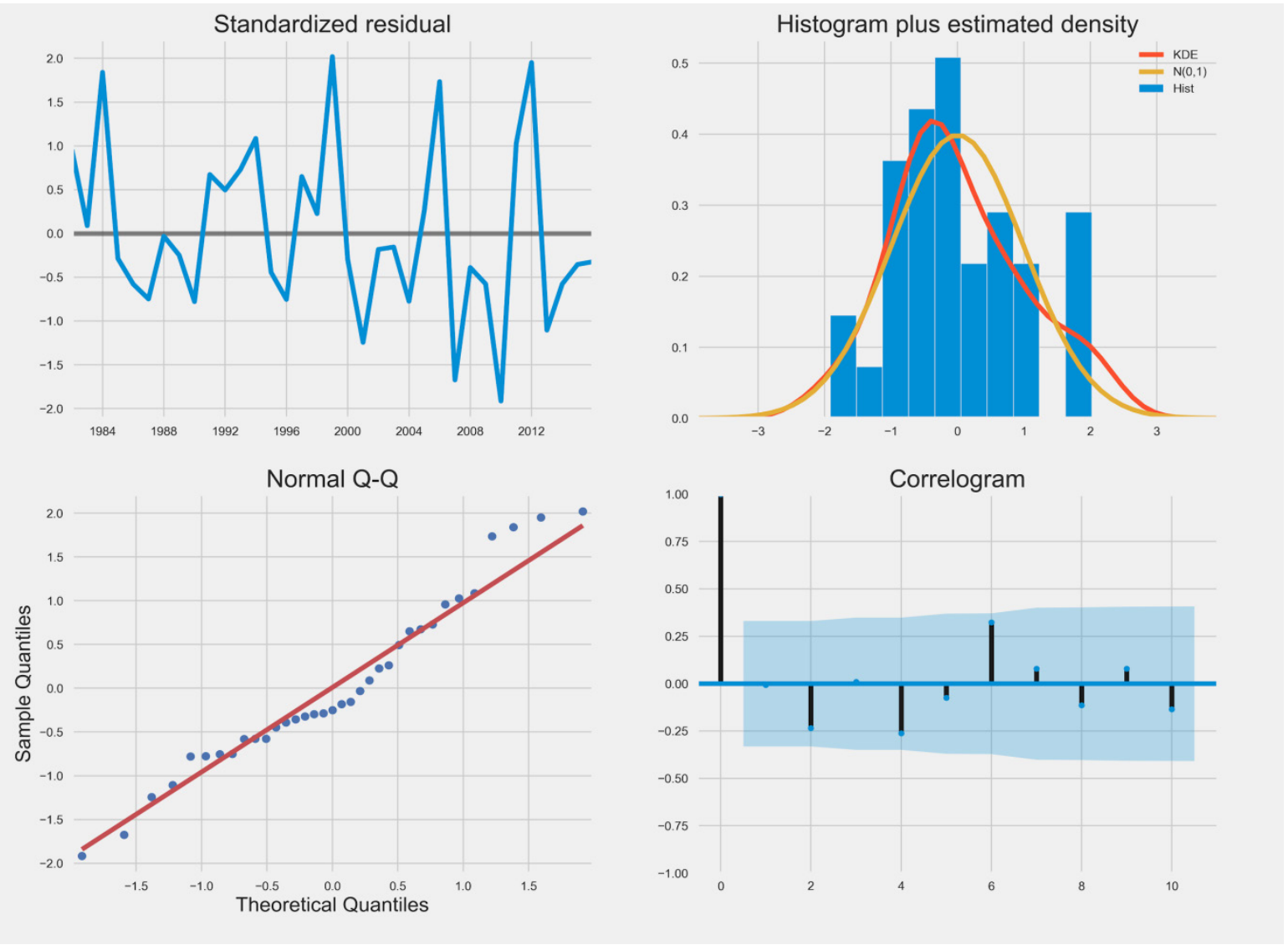

Figure 10. Diagnostic of the fitted VARMA model

Table 7 presents the characteristics of the model that was fitted with the dataset, showing the Akaike Information Criterion (AIC), the Bayesian Information Criterion (BIC) and the statistical distribution of the variables of the model, indicators of the model performance.

Figure 10 shows the VARMA results that allows us to quickly generate model diagnostics and investigate for any unusual behaviour. The top right plot shows how close is the red KDE line to the $\mathrm{N}(0,1)$ line (where $\mathrm{N}(0,1)$ ) is the standard notation for a normal distribution with mean 0 and standard deviation of 1). This is a fairly good indication that the residuals are normally distributed. The qq-plot on the bottom left gives the same information whereby the ordered distribution of residuals (blue dots) follows approximately the linear trend of the samples taken from a standard normal distribution with $\mathrm{N}(0,1)$. The residuals over time (top left plot) does not display any obvious seasonality and seems to be a complete white noise. The autocorrelation (i.e. correlogram) plot on the bottom right, confirms this by showing the time series residuals (low correlation with lagged versions of itself). The correlogram is the autocorrelation plot that displays no pattern of serial correlation. This means that the model fairly estimates values with reduced or no error that travels from point to point over time. The Mean Squared Error (MSE) and the Root Mean Squared Error (RMSE) were also checked for 
the sake of model performance.

The Mean Squared Errors and The Root Mean Squared Errors in Table 8 are good enough for the model. The RMSE values are low considering the original value's range. The RMSE has the same unit as the dependent variable.

Figure 11 reveals how fit the predicted values are with the original series. The model captures the range variations of all the input variables except the rainfall series that captures only lightly the variations (the RMSE previously discussed in Table 11 reveals this with a bit of high value compared to the range values in the series with 185.77 in a range of $382-1337 \mathrm{~mm}$ ).

Table 8. MSE and RMSE of the model on the variables

\begin{tabular}{|c|c|c|c|c|c|c|}
\hline & Tmin & Tmax & Prec & Area & Yield & Production \\
\hline Mean Squared Error (MSE) & 0.17 & 0.15 & 34510.67 & 430945.98 & 52728.08 & 978304.93 \\
\hline Root Mean Squared Error (RMSE) & 0.41 & 0.39 & 185.77 & 656.46 & 229.63 & 896.09 \\
\hline $\begin{array}{l}-\infty \text { Tmin original } \\
-\infty=\text { Tmin predicted }\end{array}$ & $\begin{array}{l}\text { - Tmax original } \\
\approx=\text { Tmax predicted }\end{array}$ & $\begin{array}{l}\rightarrow-\text { Prec original } \\
-=\text { Prec predicted }\end{array}$ & $\begin{array}{l}- \text { Areas original } \\
*=\text { Areas predicted }\end{array}$ & $\begin{array}{l}-\rightarrow \text { Productions original } \\
\approx=\text { Productions predicted }\end{array}$ & $\begin{array}{l}\because-\text { Yields original } \\
\approx=\text { Yields predicted }\end{array}$ & \\
\hline
\end{tabular}
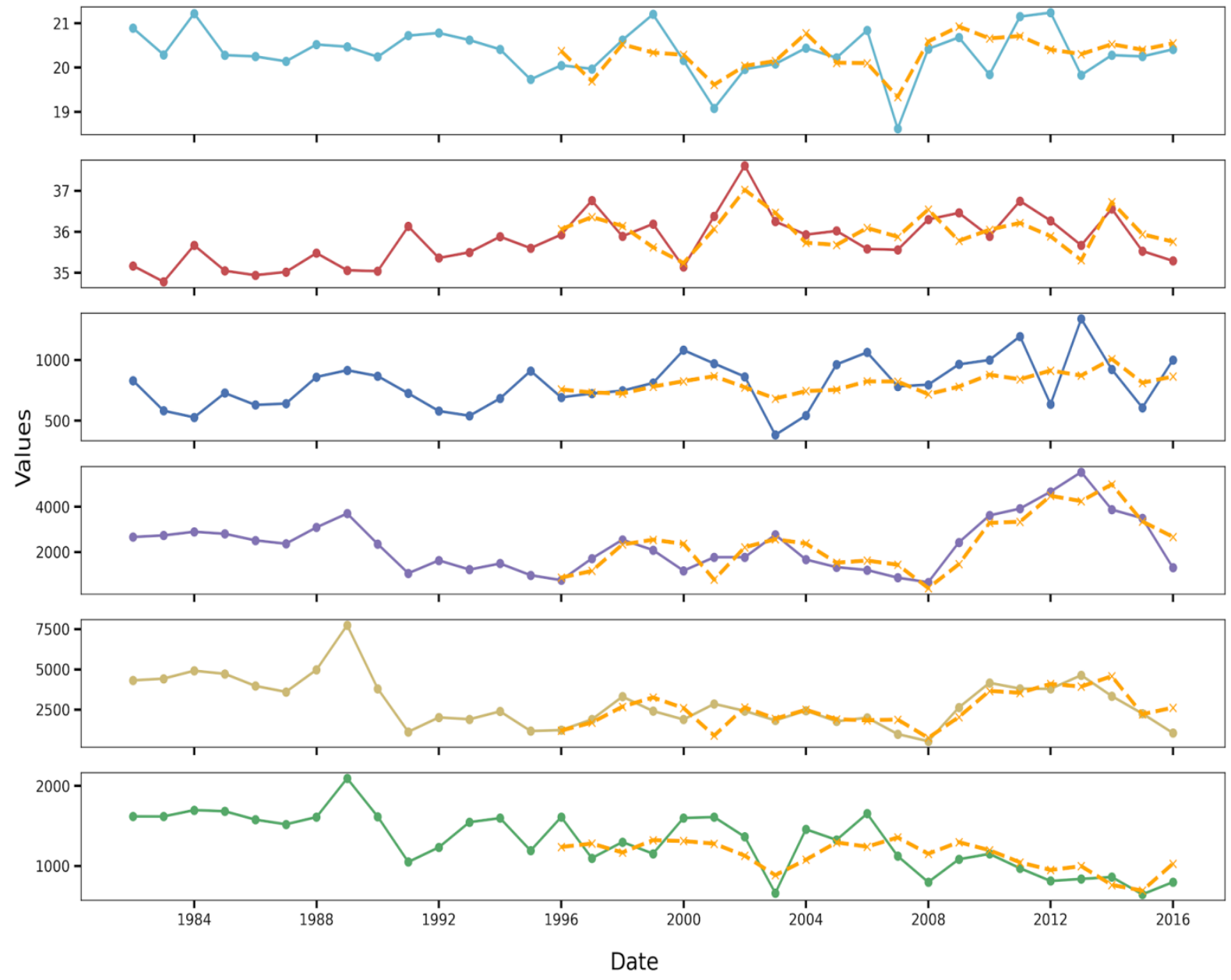

Figure 11. Visualisation of the Model's predicted values (2000-2015) with the original data (1981-2015) 

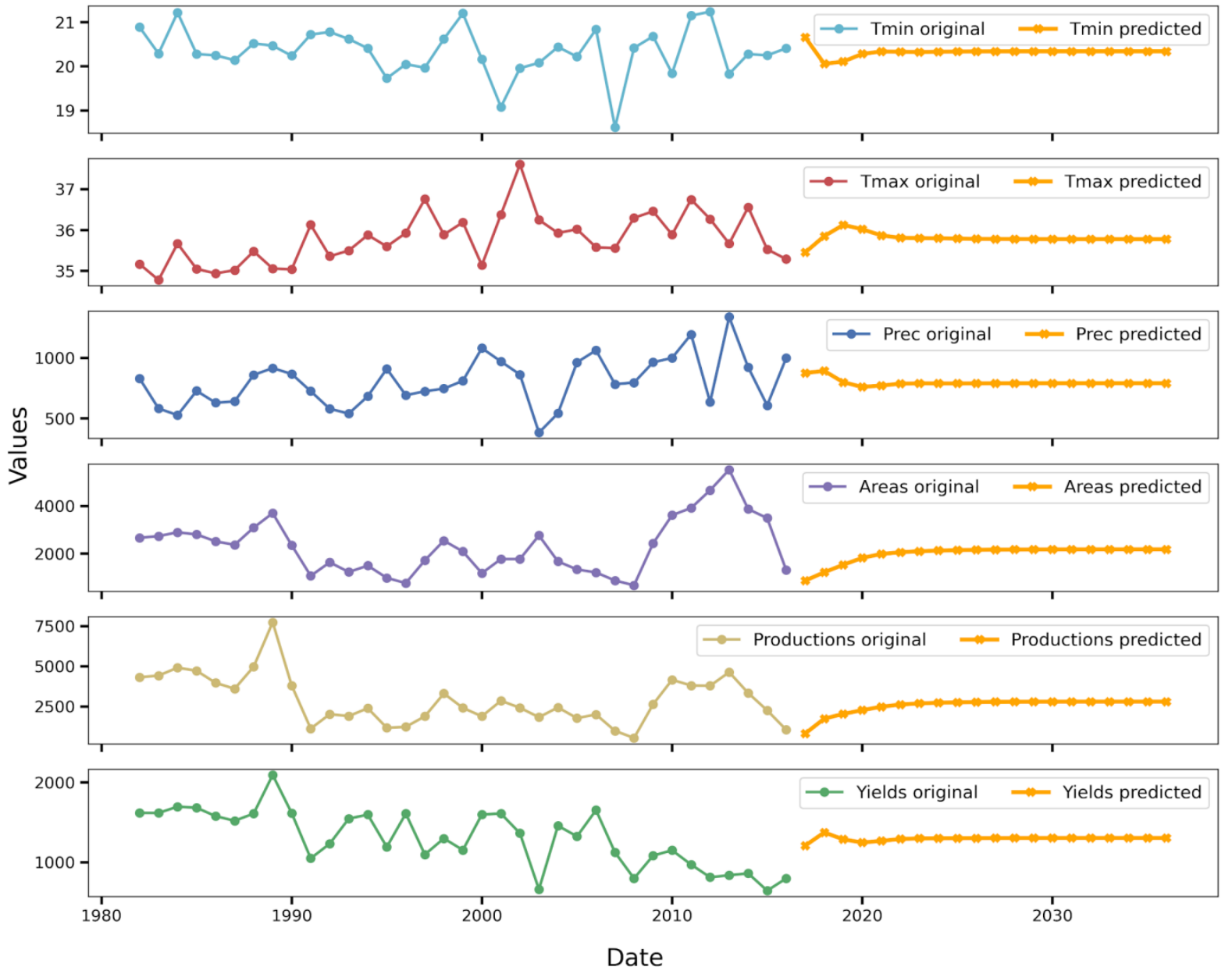

Figure 12. Future prediction values (2016-2035)

Figure 12 revealed the trend of the predicted values and the original values. This trend will increase for a time and remains approximately constant for the rest of the period. This is due to the fact that statistical models could not capture all the trends and have some limitations to project long period. It could also be due to the fact that the data used is annual data over a relatively short period.

\subsubsection{Future impacts of climate variations on rice production}

Figure 13 shows the correlation of the future predicted values from 2016 to 2035 only. The red and degraded red to white colours show strong to low positive correlations and the blue and graduated blue to white colours show strong to low negative correlations. Nothing shows a causal relationship in this analysis. The statistical relationship between the series showed a strong relationship between rainfall and production $(-0.6)$ and rainfall and harvested areas $(-0.7)$ where the existing relationships are all negative. This implies that if the rainfall decreases in the future this will increase the rice yield. A decrease in rainfall will lead to an increase in the harvested area that is basically swamp or wetland. The production negatively correlates with rainfall, if the latter decreases the production increases but this is dependent on the harvested areas as production is computed using the harvested area and the yield.

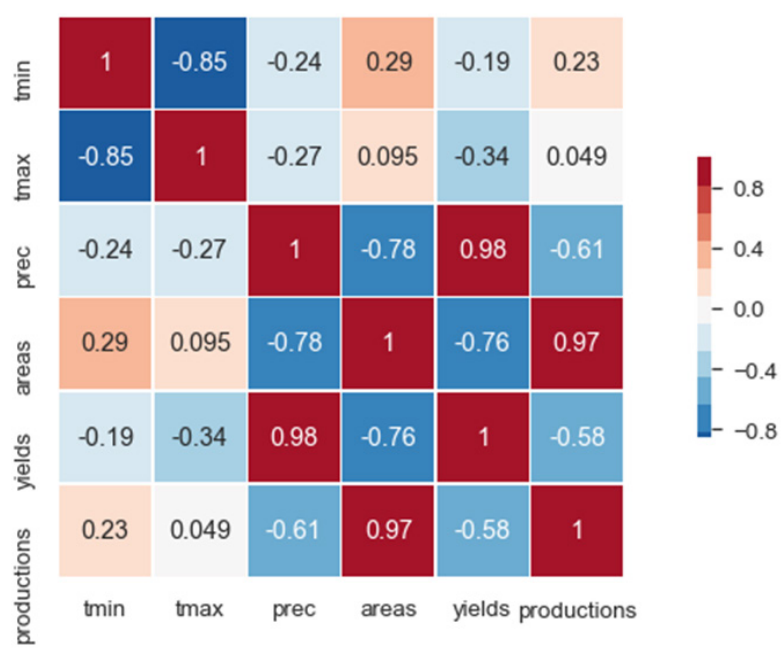

Figure 13. Correlation of the predicted values (2016 - 2035)

Table 9 shows the results of the RLM. The intercept is also correctly described as the mathematically mean 
response value when all predictor variables are set to zero. While zero setting for predictors in a model is mostly impossible, this multi-linear model is even more impossible giving almost no meaning to intercept value here. The p-value for each term or variable tests the null hypothesis that the coefficient is equal to zero (i.e. no effect or no relation). The presented results revealed significant statistical relation between each term of the predictor (climate variables) and the response (yields). This shows a meaningful step-up to the model because any change in the predictor's value is related to changes in the response variable. The maximum temperature has a $0.00 \mathrm{p}$-value, a very good relation of the latter with yields, but the relation is negatively recorded. The model coefficient is the mean change in the yields for one-unit change in each climate variable term while keeping other climate variables in the models' constant. In the case of maximum temperature, the coefficient indicates that for every additional $1{ }^{\circ} \mathrm{C}$ of maximum temperature, it is expected a decrease of yield by an average of 365.172 kilograms per hectare. Similarly, the model indicates that any $+1{ }^{\circ} \mathrm{C}$ of minimum temperature or $+1 \mathrm{~mm}$ of rainfall in the region will affect the yields to increase by $160 \mathrm{Kg} / \mathrm{ha}$ and a decrease of $\sim 0.3 \mathrm{Kg} / \mathrm{ha}$.

Table 10 presents also a statistically significant correlation between climate parameters and the average rice production in the region. But the robust linear model reveals here a rather positive relationship of rainfall on the production (about 2 metric tonnes will be added). The maximum temperature is still penalizing heavily the rice production while the minimum temperature will be a relatively similar gain.

The following Table 11 reveals that the harvested areas will reduce if the maximum temperature increases $\left(+1{ }^{\circ} \mathrm{C}\right.$ for $-219.9 \mathrm{ha}$ ) as well as the precipitation, $+1 \mathrm{~mm}$ will lead to a decrease of $\sim 1.5$ ha. Only minimum temperature will remain the good climatic factor for good rice production in the Lower River Region, in The Gambia and this must be studied to determine the threshold for Tmin too. About 404.8 ha will add to the harvest area if a $1{ }^{\circ} \mathrm{C}$ is recorded high.

Table 9. Yield and climate variables Robust Linear Regression Model Results

\begin{tabular}{|c|c|c|c|c|c|c|}
\hline Model: & \multicolumn{3}{|c|}{ RLM } & \multicolumn{2}{|c|}{ Df Residuals: } & 51 \\
\hline \multirow{2}{*}{ Dependent Variable: } & \multirow{2}{*}{\multicolumn{2}{|c|}{ Yields }} & & \multicolumn{2}{|c|}{ Norm: } & AndrewWave \\
\hline & & & & \multicolumn{2}{|c|}{ Scale Est.: } & Mad \\
\hline \multirow{3}{*}{$\begin{array}{l}\text { No. Observations: } \\
\text { Df Model: }\end{array}$} & & 55 & & \multicolumn{2}{|c|}{ Cov. Type: } & $\mathrm{H} 1$ \\
\hline & & 3 & & \multicolumn{2}{|c|}{ Scale: } & 101.93 \\
\hline & Coef. & Std.Err. & $\mathrm{z}$ & $\mathrm{P}>|\mathrm{z}|$ & {$[0.025$} & $0.975]$ \\
\hline Intercept & 11346.4738 & 1563.9046 & 7.2552 & 0.0000 & 8281.2770 & 14411.6705 \\
\hline Prec & -0.2927 & 0.1131 & -2.5871 & 0.0097 & -0.5144 & -0.0710 \\
\hline $\operatorname{Tmax}$ & -365.1725 & 36.2201 & -10.0820 & 0.0000 & -436.1625 & -294.1824 \\
\hline Tmin & 160.6037 & 42.1512 & 3.8102 & 0.0001 & 77.9888 & 243.2185 \\
\hline
\end{tabular}

Table 10. Productions and climate variables Robust Linear Regression Model Results

\begin{tabular}{|c|c|c|c|c|c|c|}
\hline Model: & \multicolumn{2}{|c|}{ RLM } & \multicolumn{3}{|c|}{ Df Residuals: } & 51 \\
\hline \multirow{2}{*}{ Dependent Variable: } & \multirow{2}{*}{\multicolumn{2}{|c|}{ Productions }} & \multicolumn{3}{|c|}{ Norm: } & AndrewWave \\
\hline & & & \multicolumn{3}{|c|}{ Scale Est.: } & Mad \\
\hline \multirow{3}{*}{$\begin{array}{c}\text { No. Observations: } \\
\text { Df Model: }\end{array}$} & \multicolumn{2}{|r|}{55} & \multicolumn{3}{|c|}{ Cov. Type: } & $\mathrm{H} 1$ \\
\hline & \multicolumn{2}{|r|}{3} & \multicolumn{3}{|c|}{ Scale: } & 643.04 \\
\hline & Coef. & Std.Err. & $\mathbf{z}$ & $\mathbf{P}>|\mathbf{z}|$ & {$[0.025$} & $0.975]$ \\
\hline Intercept & 14154.5836 & 12836.2729 & 1.1027 & 0.2702 & -11004.0490 & 39313.2161 \\
\hline Prec & 2.0492 & 0.9286 & 2.2068 & 0.0273 & 0.2292 & 3.8691 \\
\hline Tmax & -748.5360 & 297.2883 & -2.5179 & 0.0118 & -1331.2105 & -165.8616 \\
\hline Tmin & 684.0995 & 345.9702 & 1.9773 & 0.0480 & 6.0103 & 1362.1886 \\
\hline
\end{tabular}

Table 11. Areas and climate variables Robust Linear Regression Model Results

\begin{tabular}{|c|c|c|c|c|c|c|}
\hline Model: & \multicolumn{3}{|c|}{ RLM } & \multicolumn{2}{|c|}{ Df Residuals: } & 51 \\
\hline \multirow{2}{*}{ Dependent Variable: } & \multirow{2}{*}{\multicolumn{3}{|c|}{ data_pred_2035.areas }} & \multicolumn{2}{|c|}{ Norm: } & AndrewWave \\
\hline & & & & \multicolumn{2}{|c|}{ Scale Est.: } & Mad \\
\hline No. Observations: & \multicolumn{3}{|c|}{55} & \multicolumn{2}{|c|}{ Cov. Type: } & $\mathrm{H} 1$ \\
\hline \multirow[t]{2}{*}{ Df Model: } & \multicolumn{3}{|c|}{3} & \multicolumn{2}{|c|}{ Scale: } & 499.05 \\
\hline & Coef. & Std.Err. & $\mathbf{z}$ & $\mathbf{P}>|\mathbf{z}|$ & {$[0.025$} & $0.975]$ \\
\hline Intercept & 2867.9896 & 8245.5346 & 0.3478 & 0.7280 & -13292.9613 & 19028.9406 \\
\hline Prec & -1.5185 & 0.5965 & -2.5458 & 0.0109 & -2.6876 & -0.3494 \\
\hline Tmax & -219.8416 & 190.9668 & -1.1512 & 0.2496 & -594.1296 & 154.4463 \\
\hline Tmin & 404.7787 & 222.2381 & 1.8214 & 0.0686 & -30.8000 & 840.3575 \\
\hline
\end{tabular}




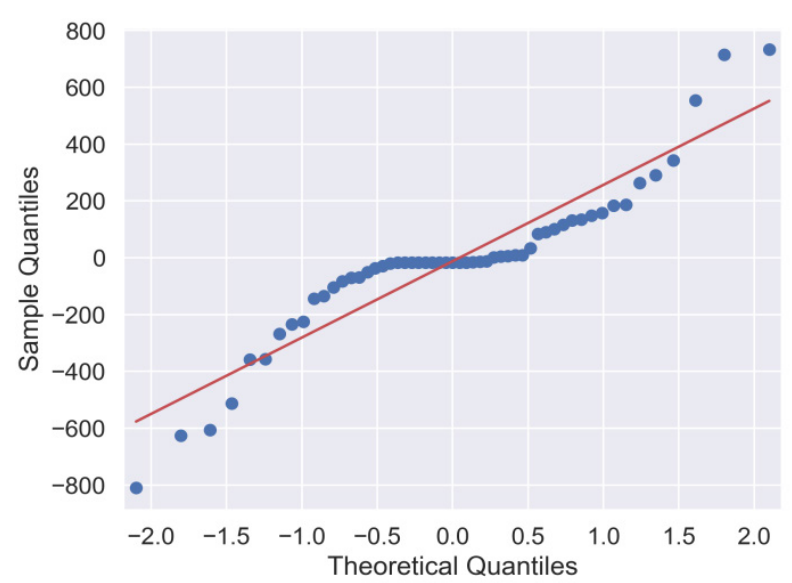

$\mathbf{a}$

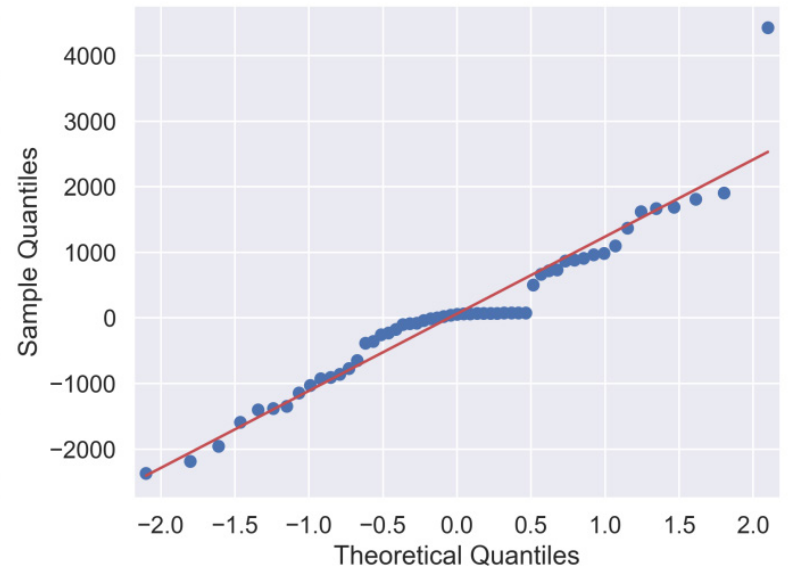

b

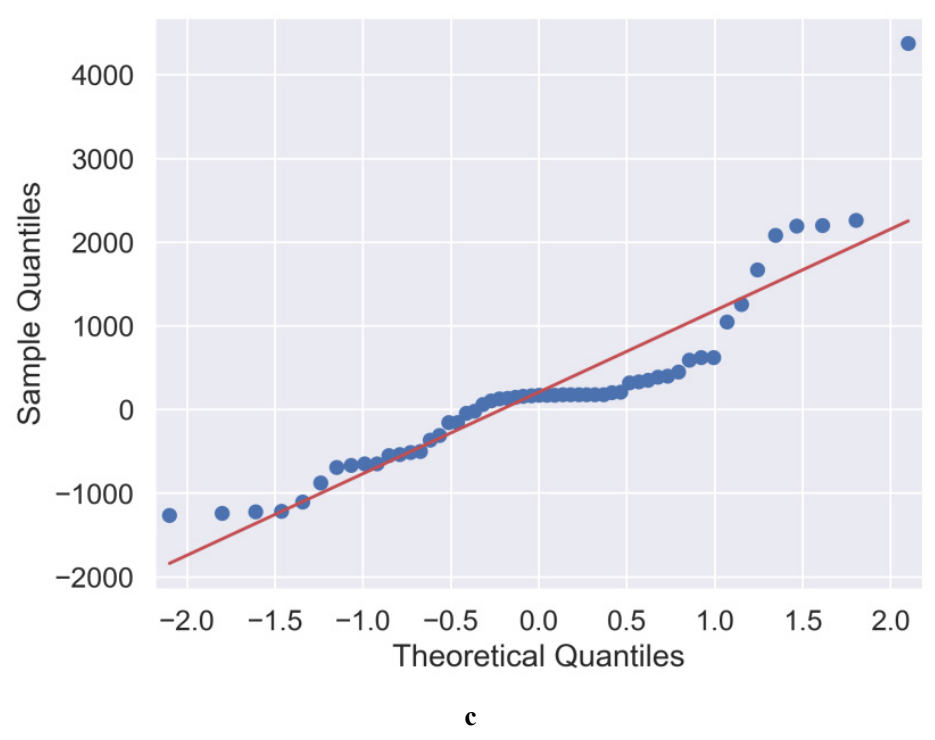

Figure 14. Robust Regression Normality Q-Q plot: a Yields; b Productions; c Areas

Figure 14 confirms the normality of the linear model considering the data that were used. The model performs well as for the multivariate analysis. They perform very similarly but the production model seems to react better to the climate parameters than the Yields and the harvested areas.

The climate parameters trends and their effects on rice production considered the rice yields, harvested area and the annual rice production. The VARMA model predicted the variables into the future (2035) using the historical records of the variables. The correlation coefficient results of the future variables revealed very high positive correlations between rainfall and yield, harvested area and production. But there the results revealed also a negative correlation between maximum and minimum temperatures $(-0.85)$. This is observed with rainfall and harvested area, harvested area and yield, production and rainfall as well as yield. This gives an idea about how rice production variables used in this analysis will behave without knowing which variable triggers the change. Generally, climate parameters have very low correlations with rice variables except for rainfall that has a negatively strong relationship with harvested area and positively strong correlation with yield. The RLM unveiled their contributions.

The increasing trend of the maximum temperature and the decreasing trend of the minimum temperature during the analysis of these two variables will increase the diurnal temperature range (DTR, the difference between daily maximum and minimum temperature) and lead to health issues that will somehow affect rice production in many ways (Lobell, 2007).

Rainfall increases when the yield decreases but production and harvested areas were increasing as well. According to the OECD, the importance of crop production is related to harvested area, returns per hectare (yields) and quantities produced. Crop yields are then, the harvested production per unit of harvested area for crop products. Yield data are not recorded, but they are computed by dividing the production records by the harvested area. The OECD specified the intervention of the genetic potential, 
the sunlight's amount received, the water and the nutrients absorbed by the crop, the presence of weed and pests in crop production. This discloses that climate parameters only cannot define very well the effect on crop production and the increase in the rainfall of the LRR will not necessarily increase the yields. The harvested area and the production have also increased from 2008 as well as the rainfall while the yields were decreasing.

The relationship between maximum temperature and the rice variables is very critical as the sunlight is one of the criteria that defines the rice yield and production. The temperature is recording extreme values (up to $47{ }^{\circ} \mathrm{C}$ monthly average); the maximum temperature is affecting the rice production in the region. If this continues to increase as the robust linear regression shows, the rice production will reduce considerably. The rice genetics must be reviewed in this situation and adapted to climate variability and especially the increase in the maximum temperature. It has been shown in extreme temperature analysis that the minimum temperature under climate change may reduce causing very cold days and cold waves (Gu et al., 2008; Kodra, Steinhaeuser, \& Ganguly, 2011; Rahmstorf \& Coumou, 2011) and this is observed in this case where the minimum temperature is not increasing but varies over the year without significant change over the time. This will be beneficial for the rice production as the minimum temperature does not really change over the year (only slight variations were recorded), that is why this condition will continue to be good for rice production and the RLM will be showing an increase of rice yield, production and even the harvested area per unit increase of this climate variable.

An important factor in the results of the model to highlight is that when the effects of the maximum and the minimum temperatures are compared, the effects of the first are more important. This could lead to a general decrease of rice production in the region if the same conditions are maintained. Climate change according to studies (Arroyo-Rodríguez, Saldaña-Vázquez, Fahrig, \& Santos, 2017; Lenderink \& Van Meijgaard, 2008; Rahmstorf \& Coumou, 2011; Schär et al., 2004; Seneviratne, Donat, Mueller, \& Alexander, 2014; Sutton et al., 2010; Vuuren et al., 2009), is anticipated to increase temperatures in the future which, in turn may strongly affect rice production.

The results here are a warning toward climate change, a serious phenomenon to which the West African Region has always been very vulnerable, knowing that our countries are agrarian based economies.

\section{Conclusions}

Climate change should be a focus in The Gambia as well as in the other countries of West Africa. Staple crops should be adaptable to the extreme climatic conditions that are expected in the very near future. Cultural practices should also be reviewed with the agricultural techniques to store water and use it later for irrigation, because while the maximum temperature is increasing, flash floods might occur the region; they are known to destroy crops; hence, affecting productions and yields.

There is a need for improved rice varieties that are early maturing, high yielding, heat tolerant and saline tolerant varieties that suit the new climatic conditions that will prevail in the region in the future. Global and local rice production has to meet future population demands; hence there is a need for more research in the area. With reference to temperature (especially the maximum temperature), there are mitigation programs like the Nationally Determined Contribution (NDCs) previously known as the Intended Nationally Determined Contribution (INDCs) for every country, and The Gambia as well as other countries need to carefully implement them to avoid future warming of the climate while combating the impacts with adaptation measures.

More studies on the effect of climate change on rice production are needed. It will be good to further this study by combining in the future more of the parameters defined by the OECD and the FAO for rice production and yields in order to improve on the model, and the use of more sophisticated models in that case as machine learning models are based on more probabilistic assumptions. A dynamical model in the region will be a plus to future studies in the LRR of The Gambia.

\section{Acronyms}

OECD: Organisation for Economic Co-operation and Development

FAO: Food and Agriculture Organization of the United Nations.

\section{Author Contributions}

M.B. designed the project, collected the data and wrote the manuscript; D.S.R. performed the data analysis, and wrote the manuscript draft; S.O.S. and I.K.E. appended their valuable comments to the manuscript.

\section{Conflicts of Interests}

The authors declare that they have no competing interests.

\section{Acknowledgements}

Our appreciations go to the West African Science Service Centre on Climate Change and Adapted Land Use 
(WASCAL) funded by the Federal Ministry of Education and Research (BMBF), Germany for funding the programme. The authors are thankful to the University of The Gambia Doctoral Research Programme in Climate Change and Education for the support. We are also grateful to the Department of Water Resources (DWR) and the Department of Planning Services of Agriculture of The Gambia, for providing the data that served for the analysis. We address our profound gratitude to Dr. Ebrima Sonko for his support in getting some of the agricultural data needed for this study. We would like to thank Prof. Sidat Yaffa (Director of WASCAL Doctoral Research Programme/University of The Gambia), Dr. Alagie Bah and Dr. Mamma Sawaneh for their priceless advices. Special thanks go to the python software foundation that continues to provide data science tools for data analysis.

\section{REFERENCES}

[1] Aboagye-Sarfo, P., Mai, Q., Sanfilippo, F. M., Preen, D. B., Stewart, L. M., \& Fatovich, D. M. (2015). A comparison of multivariate and univariate time series approaches to modelling and forecasting emergency department demand in Western Australia. Journal of Biomedical Informatics. https://doi.org/10.1016/j.jbi.2015.06.022

[2] Abzalov, M. (2016). Exploratory data analysis. In Modern Approaches in Solid Earth Sciences. https://doi.org/10.1007/978-3-319-39264-6 15

[3] Adhikari, U., Nejadhashemi, A.P. and Woznicki, S.A. (2015) Climate Change and Eastern Africa: A Review of Impact on Major Crops. Food and Energy Security, 4, 110-132. https://doi.org/10.1002/fes3.61

[4] AGRER. (2017). AGRER, I(April, 2017), 152.

[5] Aguilera, F., Orlandi, F., Ruiz-Valenzuela, L., Msallem, M., \& Fornaciari, M. (2015). Analysis and interpretation of long temporal trends in cumulative temperatures and olive reproductive features using a seasonal trend decomposition procedure. Agricultural and Forest Meteorology. https://doi.org/10.1016/j.agrformet.2014.11.019

[6] Al-Amin, A. Q., \& Ahmed, F. (2016). Food Security Challenge of Climate Change: An Analysis for Policy Selection. Futures, 83, 50-63. https://doi.org/10.1016/j.futu res.2016.04.002

[7] Ali, A., \& Qadir, M. F. (2015). A Modified M-estimator for the Detection of Outliers. Pakistan Journal of Statistics and Operation Research, 1(1), 49. https://doi.org/10.18187/pjso r.v1i1.116

[8] Andrews, D. F. (1974). A robust method for multiple linear regression. Technometrics. https://doi.org/10.1080/0040170 6.1974 .10489233

[9] Andrews, D. F., \& Pregibon, D. (1978). Finding the Outliers that Matter. Journal of the Royal Statistical Society: Series B (Methodological).

https://doi.org/10.1111/j.2517-6161.1978.tb01652.x
[10] Andrienko, N., \& Gennady, A. (2006). Exploratory analysis of spatial and temporal data: A systematic approach. Exploratory Analysis of Spatial and Temporal Data: A Systematic Approach.https://doi.org/10.1007/3-540-311904

[11] Bagbohouna, M., Yaffa, S. \& Bah, A. (2018). The Impacts of Saline-Water Intrusion on the Lives and Livelihoods of Gambian Rice- Growing Farmers. Journal of Ecology and Environmental Sciences, 6(1), pp.1-7.http://www.rroij.com /open-access/the-impacts-of-salinewater-intrusion-on-theliv es-and-livelihoods-of-gambian-ricegrowingfarmers.pdf

[12] Bagbohouna, M., Yaffa, S., Sogbedji, J. M., Bah, A., \& Koglo, S.Y. (2018). Knowledge and Adaptive Responses of Rice Farmers to Saline-water Intrusion on Swamp Rice-growing Fields in Lower River Region of the Gambia. , 8(3), pp.63-76. http://iiste.org/Journals/index.php/JEES/arti cle/view/41593/42815

[13] Baker, K. R. (1977). AN EXPERIMENTAL STUDY OF THE EFFECTIVENESS OF ROLLING SCHEDULES IN PRODUCTION PLANNING. Decision Sciences. https://doi.org/10.1111/j.1540-5915.1977.tb01065.x

[14] Beguería, S., \& Pueyo, Y. (2009). A comparison of simultaneous autoregressive and generalized least squares models for dealing with spatial autocorrelation. Global Ecology and Biogeography. https://doi.org/10.1111/j.14668238.2009.00446.x

[15] Bisgaard, S., \& Kulahci, M. (2009). Quality Quandaries*: Time Series Model Selection and Parsimony. Quality Engineering. https://doi.org/10.1080/08982110903025197

[16] Bolker, B. M. (2019). Exploratory Data Analysis and Graphics. In Ecological Models and Data in $R$. https://doi.org/10.2307/j.ctvem4g37.5

[17] Carslaw, D. C. (2005). On the changing seasonal cycles and trends of ozone at Mace Head, Ireland. Atmospheric Chemistry and Physics. https://doi.org/10.5194/acp-5-34412005

[18] Chattopadhyay, A. K., \& Chattopadhyay, T. (2014). Time series analysis. In Springer Series in Astrostatistics. https://doi.org/10.1007/978-1-4939-1507-1_9

[19] Chen, Y. (2012). On the four types of weight functions for spatial contiguity matrix. Letters in Spatial and Resource Sciences. https://doi.org/10.1007/s12076-011-0076-6

[20] Christensen, R. (2011). One-Way ANOVA. https://doi.org/10.1007/978-1-4419-9816-3_4

[21] Clark, P. U., Shakun, J. D., Marcott, S. A., Mix, A. C., Eby, M., Kulp, S., ... Plattner, G. K. (2016). Consequences of twenty-first-century policy for multi-millennial climate and sea-level change. Nature Climate Change, 6(4), 360-369. https://doi.org/10.1038/nclimate2923

[22] Cleveland, R. B., Cleveland, W. S., McRae, J. E., \& Terpenning, I. (1990). STL: A Seasonal-Trend Decomposition Procedure Based on Loess. Journal of Official Statistics.

[23] Cohen, J. (1988). Statistical power analysis for the behavioral sciences, second edition. Statistical Power Analysis for the Behavioral Sciences. https://doi.org/10.123 $4 / 12345678$ 
[24] Contreras, J., Espínola, R., Nogales, F. J., \& Conejo, A. J. (2003). ARIMA models to predict next-day electricity prices. IEEE Transactions on Power Systems. https://doi.org/10.11 09/TPWRS.2002.804943

[25] Dendukuri, N., \& Reinhold, C. (2005). Correlation and regression. American Journal of Roentgenology. https://doi.org/10.2214/ajr.185.1.01850003

[26] Dickey, D. A., \& Pantula, S. G. (1987). Determining the order of differencing in autoregressive processes. Journal of Business and Economic Statistics. https://doi.org/10.1080/0 7350015.1987.10509614

[27] Du Toit, S. H. C., \& Browne, M. W. (2007). Structural equation modeling of multivariate time series. Multivariate Behavioral Research. https://doi.org/10.1080/00273170701 340953

[28] Fatajo, F. S. (2009). NATIONAL ISSUES REPORT ON KEY SECTOR OF AGRICULTURE (ADAPTATION) IN THE GAMBIA Prepared and Presented By.

[29] Gasparella, A., Pernigotto, G., Cappelletti, F., Romagnoni, P., \& Baggio, P. (2011). Analysis and modelling of window and glazing systems energy performance for a well insulated residential building. Energy and Buildings. https://doi.org/1 0.1016/j.enbuild.2010.12.032

[30] GBOS. (2017). Statistical Abstract.

[31] Gelman, A. (2004). Exploratory data analysis for complex models. Journal of Computational and Graphical Statistics. https://doi.org/10.1198/106186004X11435

[32] Government of The Gambia (2007). Climate change in The Gambia. United Nations Development Programme in Collaboration with the Government of Norway. 23pp.

[33] Goldstein, H., Cohen, J., \& Cohen, P. (2006). Applied Multiple Regression/Correlation Analysis for the Behavioural Sciences. Journal of the Royal Statistical Society. Series A (General). https://doi.org/10.2307/234436 7

[34] Guidolin, M. (2018). Vector Autoregressive Moving Average (VARMA) Models.

[35] Haining, R. (2015). Spatial Autocorrelation. In International Encyclopedia of the Social \& Behavioral Sciences: Second Edition.

https://doi.org/10.1016/B978-0-08-097086-8.72056-3

[36] Hall, A. (1994). Testing for a unit root in time series with pretest data-based model selection. Journal of Business and Economic Statistics.https://doi.org/10.1080/07350015.1994 .10524568

[37] Hayes, A. F., \& Cai, L. (2007). Using heteroskedasticity-consistent standard error estimators in OLS regression: An introduction and software implementation. Behavior Research Methods. https://doi.org/10.3758/BF03192961

[38] Hurvich, C. (2010). 21 : Differencing and unit root tests. Time Series Notes.

[39] Hyndman, R. J. (2015). Discussion of "High-dimensional autocovariance matrices and optimal linear prediction." Electronic Journal of Statistics. https://doi.org/10.1214/14EJS953
[40] Im, K. S., Pesaran, M. H., \& Shin, Y. (2003). Testing for unit roots in heterogeneous panels. Journal of Econometrics. https://doi.org/10.1016/S0304-4076(03)00092-7

[41] IPCC. (2007). Climate change 2007 : impacts, adaptation and vulnerability: Working Group II contribution to the Fourth Assessment Report of the IPCC Intergovernmental Panel on Climate Change. Working Group II Contribution to the Intergovernmental Panel on Climate Change Fourth Assessment Report, 1(July), 976. https://doi.org/10.2134/jeq $2008.0015 \mathrm{br}$

[42] Jersky, B. (2009). Exploratory Data Analysis With MATLAB. Journal of the American Statistical Association. https://doi.org/10.1198/jasa.2006.s82

[43] Jiang, B., Liang, S., Wang, J., \& Xiao, Z. (2010). Modeling MODIS LAI time series using three statistical methods. Remote Sensing of Environment. https://doi.org/10.1016/j.rs e.2010.01.026

[44] Johnson, L. W., \& Girden, E. R. (2006). ANOVA: Repeated Measures. Journal of Marketing Research. https://doi.org/1 $0.2307 / 3152054$

[45] Judd, C. M., McClelland, G. H., Ryan, C. S., Judd, C. M., McClelland, G. H., \& Ryan, C. S. (2018). One-Way ANOVA. In Data Analysis. https://doi.org/10.4324/978131 5744131-8

[46] Kalpakis, K., Gada, D., \& Puttagunta, V. (2002). Distance measures for effective clustering of ARIMA time-series. https://doi.org/10.1109/icdm.2001.989529

[47] Kascha, C., \& Trenkler, C. (2015). Simple identification and specification of cointegrated VARMA models. Journal of Applied Econometrics, 30(4), 675-702.

[48] Keith Ord, J., \& Getis, A. (2001). Testing for local spatial autocorrelation in the presence of global autocorrelation. Journal of Regional Science.https://doi.org/10.1111/0022-4 146.00224

[49] Kilmer, J. T., \& Rodríguez, R. L. (2017). Ordinary least squares regression is indicated for studies of allometry. Journal of Evolutionary Biology. https://doi.org/10.1111/jeb.12986

[50] Kissling, G. E. (2017). Statistical methods. In The Clinical Chemistry of Laboratory Animals, Third Edition. https://doi.org/10.1201/9781315155807

[51] Komba, C. and Muchapondwa, E. (2015) Adaptation to Climate Change by Smallholder Farmers in Tanzania. Discussion Paper Series, Environment for Development (EfD) $15-12$

[52] Kotir, J. H. (2011). Climate change and variability in Sub-Saharan Africa: A review of current and future trends and impacts on agriculture and food security. Environment, Development and Sustainability, 13(3), 587-605. https://doi.org/10.1007/s10668-010-9278-0

[53] Kropff, R. B. M. M. J., Horie, T., \& Bacheletd, D. (1997). Simulating the Impact of Climate Change on Rice Production in Asia and Evaluating Options for Adaptation, Agricultural Systems, 54(3), 399-425. https://doi.org/10.10 16/S0308-521X(95)00060-I

[54] Kumar, U., \& Jain, V. K. (2010). ARIMA forecasting of ambient air pollutants (O 3, NO, NO 2 and CO). Stochastic 
Environmental Research and Risk Assessment. https://doi.org/10.1007/s00477-009-0361-8

[55] Kumar, V., Singh, A., Adhikary, M., Daral, S., Khokhar, A., \& Singh, S. (2014). Seasonality of Tuberculosis in Delhi, India: A Time Series Analysis. Tuberculosis Research and Treatment. https://doi.org/10.1155/2014/514093

[56] Luetkepohl, H. (2004). Forecasting with VARMA Models. Handbook of Economic Forecasting, 1, 296-304. https://doi.org/10.1016/S1574-0706(05)01006-2

[57] Manning, W. G., Basu, A., \& Mullahy, J. (2005). Generalized modeling approaches to risk adjustment of skewed outcomes data. Journal of Health Economics. https://doi.org/10.1016/j.jhealeco.2004.09.011

[58] Markowitz, J. S. (2018). Multivariate analysis. In SpringerBriefs in Public Health. https://doi.org/10.1007/97 8-3-319-77203-5 8

[59] Martin. (1000). Two-way ANOVA and ANCOVA. None. https://doi.org/10.1002/9781118491683

[60] Martin Bland, J., \& Altman, D. G. (1986). STATISTICAL METHODS FOR ASSESSING AGREEMENT BETWEEN TWO METHODS OF CLINICAL MEASUREMENT. The Lancet. https://doi.org/10.1016/S0140-6736(86)90837-8

[61] McHugh, M. L. (2011). Multiple comparison analysis testing in ANOVA. Biochemia Medica.

[62] McKean, H. E. (1969). Statistical Tables. Technometrics. https://doi.org/10.1080/00401706.1969.10490749

[63] MHAMDI, F., POGGI, J.-M., \& JAÏDANE, M. (2011). TREND EXTRACTION FOR SEASONAL TIME SERIES USING ENSEMBLE EMPIRICAL MODE DECOMPOSITION. Advances in Adaptive Data Analysis. https://doi.org/10.1142/s1793536911000696

[64] Mills, T. C., \& Mills, T. C. (2014). Autocorrelation. In Analysing Economic Data. https://doi.org/10.1057/9781137 40190814

[65] Ministry of Agriculture (MOA) The Gambia (2013). http://www.moa.gov.gm/

[66] Moutinho, L., Hutcheson, G., Hutcheson, G., \& Hutcheson, G. (2014). Ordinary Least-Squares Regression. In The $S A G E$ Dictionary of Quantitative Management Research. https://doi.org/10.4135/9781446251119.n67

[67] Mukaka, M. M. (2012). Statistics corner: A guide to appropriate use of correlation coefficient in medical research. Malawi Medical Journal.

[68] Muller, K. (2012). Statistical Power Analysis for the Behavioral Sciences. Technometrics. https://doi.org/10.108 0/00401706.1989.10488618

[69] Mushtaq, R. (2011). Augmented Dickey Fuller Test. SSRN. https://doi.org/10.2139/ssrn.1911068

[70] NAPA. (2007).

[71] Ngo, T. H. D. (2013). The Box-Jenkins Methodology for Time Series Models. SAS Global Forum 2013.

[72] Pak, S. Il, \& Oh, T. H. (2010). Correlation and simple linear regression. Journal of Veterinary Clinics.
[73] Parmar, K. S., \& Bhardwaj, R. (2014). Statistical, time series, and fractal analysis of full stretch of river yamuna (India) for water quality management. Environmental Science and Pollution https://doi.org/10.1007/s11356-014-3346-1 Research.

[74] Peng, S., Huang, J., Sheehy, J. E., Laza, R. C., Visperas, R. M., Zhong, X., Centeno, G.S., Khush, G. S., \& Cassman, K. G. (2004). Rice yields decline with higher night temperature from global warming. Proceedings of the National Academy of Sciences of the United States of America. July 6, 2004101 (27) 9971-9975; https://doi.org/10.1073/pnas.0403720101

[75] Phillips, P. C. B., \& Perron, P. (1988). Testing for a unit root in time series regression. Biometrika. https://doi.org/10.109 3/biomet/75.2.335

[76] Pohlmann, J. T., \& Leitner, D. W. (2003). A Comparison of Ordinary Least Squares and Logistic Regression. The Ohio Journal of Science.

[77] Pourahmadi, M. (1986). ON STATIONARITY OF THE SOLUTION OF A DOUBLY STOCHASTIC MODEL. Journal of Time Series Analysis. https://doi.org/10.1111/j.1 467-9892.1986.tb00490.x

[78] Priestley, M. B., \& Rao, T. S. (1969). A Test for Non-Stationarity of Time-Series. Journal of the Royal Statistical

Society: Series B (Methodological). https://doi.org/10.1111/ j.2517-6161.1969.tb00775.x

[79] Pulver EL, Nguyen VN (1999) Sustainable rice production issues for the third millennium. In: Proceedings of the 19th session of the international rice commission held from 7-9 September 1998 in Cairo, Egypt, pp 32-44

[80] Ragatoa, D. S., Ogunjobi, K. O., Okhimamhe, A. A., Francis, S. D., \& Adet, L. (2018). A Trend Analysis of Temperature in Selected Stations in Nigeria Using Three Different Approaches. OALib, 05(02), 1-17.https://doi.org/10.4236/o alib.1104371

[81] Refinetti, R. (2004). Non-stationary time series and the robustness of circadian rhythms. Journal of Theoretical Biology. https://doi.org/10.1016/j.jtbi.2003.11.032

[82] Rojo, J., Rivero, R., Romero-Morte, J., Fernández-González, F., \& Pérez-Badia, R. (2017). Modeling pollen time series using seasonal-trend decomposition procedure based on LOESS smoothing. International Journal of Biometeorology. https://doi.org/10.1007/s00484-016-1215-y

[83] Sanchez-Vazquez, M. J., Nielen, M., Gunn, G. J., \& Lewis, F. I. (2012). Using seasonal-trend decomposition based on loess (STL) to explore temporal patterns of pneumonic lesions in finishing pigs slaughtered in England, 2005-2011. Preventive Veterinary Medicine.https://doi.org/10.1016/j.pr evetmed.2011.11.003

[84] Schiegg, K. (2003). Environmental autocorrelation: Curse or blessing? Trends in Ecology and Evolution. https://doi.org/ 10.1016/S0169-5347(03)00074-0

[85] Segurado, P., Araújo, M. B., \& Kunin, W. E. (2006). Consequences of spatial autocorrelation for niche-based models. Journal of Applied Ecology.https://doi.org/10.1111 j.1365-2664.2006.01162.x

[86] Shaw, R. G., \& Mitchell-Olds, T. (1993). ANOVA for unbalanced data: an overview. Ecology. https://doi.org/10.2 
$307 / 1939922$

[87] Sheng, Y., \& Song, L. (2019). Agricultural production and food consumption in China: A long-term projection. China Economic Review, 53(August 2018), 15-29. https://doi.org/ 10.1016/j.chieco.2018.08.006

[88] Silawan, T., Singhasivanon, P., Kaewkungwal, J., Nimmanitya, S., \& Suwonkerd, W. (2008). Temporal patterns and forecast of dengue infection in Northeastern Thailand. Southeast Asian Journal of Tropical Medicine and Public Health.

[89] Smalheiser, N. R. (2017). ANOVA. In Data Literacy. https://doi.org/10.1016/b978-0-12-811306-6.00011-7

[90] Sonko, E., \& Agodzo, S. K. (2019). Evaluating the Yield Response of Maize (Zea mays L.) and Rice (Oryza sativa L.) to Future Climate Variability in The Gambia. Journal of Agricultural Studies, 7(2), 11-26.

[91] Sonko, E., Florkowski, W., Agodzo, S., \& Antiwe-Agyei, P. (2019). Farmer choice of strategies alleviating food insecurity due to changing weather patterns.

[92] Sovann, N., Nallagownden, P., \& Baharudin, Z. (2014). A method to determine the input variable for the neural network model of the electrical system. In 2014 5th International Conference on Intelligent and Advanced Systems: Technological Convergence for Sustainable Future, ICIAS 2014 - Proceedings. https://doi.org/10.1109/ICIAS.2 014.6869491

[93] Spitznagel, E. L. (2007). 6 Logistic Regression. Handbook of Statistics. https://doi.org/10.1016/S0169-7161(07)270063

[94] Sthle, L., \& Wold, S. (1989). Analysis of variance (ANOVA). Chemometrics and Intelligent Laboratory Systems. https://doi.org/10.1016/0169-7439(89)80095-4

[95] Suhartono. (2011). Time Series Forecasting by using Seasonal Autoregressive Integrated Moving Average: Subset, Multiplicative or Additive Model. Journal of Mathematics and Statistics. https://doi.org/10.3844/jmssp.2 011.20 .27

[96] Tarno, Subanar, Rosadi, D., \& Suhartono. (2012). New procedure for determining order of subset Autoregressive Integrated Moving Average (ARIMA) based on over-fitting concept. In ICSSBE 2012 - Proceedings, 2012 International Conference on Statistics in Science, Business and Engineering: "Empowering Decision Making with Statistical Sciences. ”https://doi.org/10.1109/ICSSBE.2012.
6396643

[97] UNECA. (2017). The gambia.

[98] Vinod, H. D. (2006). Maximum entropy ensembles for time series inference in economics. Journal of Asian Economics. https://doi.org/10.1016/j.asieco.2006.09.001

[99] Vogt, W. (2015). Three-Way ANOVA. In Dictionary of Statistics \& Methodology. https://doi.org/10.4135/9781412 983907.n1974

[100] Wassertheil, S., \& Cohen, J. (2006). Statistical Power Analysis for the Behavioral Sciences. Biometrics. https://doi.org/10.2307/2529115

[101] Webb, J. L. A. J. (1992). The Royal African Society Ecological and Economic Change along the Middle Reaches of the Gambia River, 1945-1985 Author (s): James L. A. Webb, Jr. Published by : Oxford University Press on behalf of The Royal African Society Stable URL: http://www.jstor.org/stable/722989, 91(365), 543-565.

[102] Weihs, C. (2005). Multivariate exploratory data analysis and graphics: A tutorial. Journal of Chemometrics. https://doi.org/10.1002/cem.1180070502

[103] Welch, J. R., Vincent, J. R., Auffhammer, M., Moya, P. F., Dobermann, A. \& Dawe, D. (2010). Rice yields in tropical/subtropical Asia exhibit large but opposing sensitivities to minimum and maximum temperatures. Proceedings of the National Academy of Sciences of the United States of America. PNAS August 17, 2010107 (33) 14562-14567; https://doi.org/10.1073/pnas.1001222107

[104] Woolrich, M. W., Ripley, B. D., Brady, M., \& Smith, S. M. (2001). Temporal autocorrelation in univariate linear modeling of FMRI data. NeuroImage. https://doi.org/10.10 06/nimg.2001.0931

[105] Xiong, T., Li, C., \& Bao, Y. (2018). Seasonal forecasting of agricultural commodity price using a hybrid STL and ELM method: Evidence from the vegetable market in China. Neurocomputing. https://doi.org/10.1016/j.neucom.2017.11.053

[106] Yurekli, K., Kurunc, A., \& Ozturk, F. (2005). Application of linear stochastic models to monthly flow data of Kelkit Stream. Ecological Modelling. https://doi.org/10.1016/j.ec olmodel.2004.08.001

[107] Zhang, P. G. (2003). Time series forecasting using a hybrid ARIMA and neural network model. Neurocomputing. https://doi.org/10.1016/S0925-2312(01)00702-0 